\title{
Brain Metastasis in Bone and Soft Tissue Cancers: A Review of Incidence, Interventions, and Outcomes
}

\author{
Faris Shweikeh, ${ }^{1}$ Laura Bukavina, ${ }^{2,3}$ Kashif Saeed, ${ }^{4}$ Reem Sarkis, ${ }^{1}$ \\ Aarushi Suneja, ${ }^{1}$ Fadi Sweiss, ${ }^{5}$ and Doniel Drazin ${ }^{6}$ \\ ${ }^{1}$ College of Medicine, Northeast Ohio Medical University, 4209 State Route 44, Rootstown, OH 44272, USA \\ ${ }^{2}$ Department of Medicine, Summa Health System, Akron, OH 44303, USA \\ ${ }^{3}$ Johns Hopkins School of Public Health, Baltimore, MD 21205, USA \\ ${ }^{4}$ Department of Physical Medicine and Rehabilitation, Rush University Medical Center, Chicago, IL 60612, USA \\ ${ }^{5}$ Department of Neurosurgery, George Washington University, Washington, DC 20037, USA \\ ${ }^{6}$ Department of Neurosurgery, Cedars-Sinai Medical Center, Los Angeles, CA 90048, USA
}

Correspondence should be addressed to Faris Shweikeh; faris.shweikeh@gmail.com

Received 30 September 2013; Revised 19 January 2014; Accepted 22 January 2014; Published 16 March 2014

Academic Editor: Shreyaskumar Patel

Copyright (C) 2014 Faris Shweikeh et al. This is an open access article distributed under the Creative Commons Attribution License, which permits unrestricted use, distribution, and reproduction in any medium, provided the original work is properly cited.

Bone and soft tissue malignancies account for a small portion of brain metastases. In this review, we characterize their incidence, treatments, and prognosis. Most of the data in the literature is based on case reports and small case series. Less than 5\% of brain metastases are from bone and soft tissue sarcomas, occurring most commonly in Ewing's sarcoma, malignant fibrous tumors, and osteosarcoma. Mean interval from initial cancer diagnosis to brain metastasis is in the range of 20-30 months, with most being detected before 24 months (osteosarcoma, Ewing sarcoma, chordoma, angiosarcoma, and rhabdomyosarcoma), some at 24-36 months (malignant fibrous tumors, malignant peripheral nerve sheath tumors, and alveolar soft part sarcoma), and a few after 36 months (chondrosarcoma and liposarcoma). Overall mean survival ranges between 7 and 16 months, with the majority surviving $<12$ months (Ewing's sarcoma, liposarcoma, malignant fibrous tumors, malignant peripheral nerve sheath tumors, angiosarcoma and chordomas). Management is heterogeneous involving surgery, radiosurgery, radiotherapy, and chemotherapy. While a survival advantage may exist for those given aggressive treatment involving surgical resection, such patients tended to have a favorable preoperative performance status and minimal systemic disease.

\section{Introduction}

It is estimated that up to $30 \%$ of patients with cancer will develop brain involvement $[1,2]$. Breast cancer, nonsmall cell lung cancer, and melanoma have shown a predilection for brain metastasis $[3,4]$. Brain metastases are 10 times more common than primary brain tumors, resulting mostly from carcinomas [1-4]. The incidence is much lower in the pediatric population with estimates of $1.5-2.5 \%$ [3].

Accounting for $0.8 \%$ of all cancers, musculoskeletal bone and soft tissue sarcomas make up a small portion of patients with brain metastases [4]. It is estimated that $3 \%$ of all brain metastases are sarcomas and $1-8 \%$ of all sarcoma patients may develop brain involvement $[1,2]$. However, there is mounting evidence that the incidence is increasing due to new chemo- and radiotherapeutic treatments that prolong survival through systemic disease control but without effective intracranial control $[2,5]$. Unlike many other brain metastases, sarcomas tend to be highly radioand chemoresistant with surgical resection as the basis for management [1]. Mechanisms of sarcoma spread to the brain are twofold: hematogenous dissemination into brain parenchyma and contiguous extension of metastases in bones of the skull into intracranial structures [6].

The purpose of this review is to present the current literature on brain metastasis (BM) from bone and soft tissue cancers, with an emphasis on musculoskeletal sarcomas and those most commonly metastasizing to the brain. 
We describe the incidence, diagnostic strategies, treatment paradigms, and prognostic outcomes as well as relevant background information.

\section{Methods}

A search of the published literature was conducted for patients with brain metastasis from musculoskeletal sarcomas. The national library of medicine search engine, PubMed, was utilized for the literature search. For each of the sarcomas, the search terms "brain" and "intracranial" were combined with the tumor's name: "osteosarcoma," "Ewing's sarcoma," "chondrosarcoma," "chordoma," "malignant fibrous tumor," "malignant fibrous histiocytoma," "fibrosarcoma," "liposarcoma," "alveolar soft part sarcoma," "rhabdomyosarcoma," "malignant peripheral nerve sheath tumor," "MPNST," or "angiosarcoma." Relevant articles describing case reports or clinical studies were selected, and the reference lists from these articles were also inspected for other relevant articles. Each of the resultant articles were examined closely and reported in this review. Cases in which there was contiguous extension of a primary tumor into intracranial structures (i.e., a skull tumor) as opposed to frank metastasis from a distant site were excluded. Only publications in English, peerreviewed journals were included.

\section{Results}

3.1. Malignant Bone Tumors. The primary malignant bone tumors discussed are the most commonly reported to metastasize to the brain: osteosarcoma (osteogenic sarcoma), Ewing's sarcoma, chondrosarcoma, chordoma, and fibroblastic/fibrohistiocytic tumors.

3.1.1. Osteosarcoma (Osteogenic Sarcoma). After plasmacytoma $(33 \%)$, osteosarcoma $(20 \%)$ is the most frequently occurring primary malignant bone tumor [7], characterized by osteoid producing atypical cells [8]. In children, osteosarcoma is the most common bone cancer [9]. Dissemination is typically via the bloodstream, primarily targeting lungs and other bones [10]. BM is rare, with a reported incidence of 1.8$5.6 \%$ [3], and associated with prior pulmonary metastasis [11], with the hypothesis of lung tumor emboli invading the brain. Nonetheless, there are several reports of BM without active lung involvement. An increased risk of BM with metastatic disease at presentation or with recurrence at 1 year has been reported [3]. As in other BM, those from osteosarcoma typically locate through the anterior circulation to the graywhite matter junction [12]. Multimodality treatment is often involved, though no consensus on treatment exists.

Table 1 summarizes published cases of osteosarcoma patients with BM $[2-5,9,13-28]$. A total of 55 patients are presented, with an average age of 18 years and a male: female ratio of $3: 2$. Location of the primary was variable, with majority localized to the femur. BM management almost always involved surgical resection (SR). This was followed by whole brain radiation therapy (WBRT) and/or chemotherapy in select cases. Mean interval to BM from initial diagnosis
(IB) was approximately $18.9 \pm 21.1$ months (range $0-110$ ) from diagnosis of the primary, and overall mean survival (OS) was approximately $18.4 \pm 30.4$ months following its detection. A possible predilection for synchronous metastasis has also been highlighted $[13,14]$. Location of metastatic lesions varied throughout the cerebrum with the frontal lobe being the most common single lesion.

Yonemoto et al. [18] recommended performing brain imaging periodically in patients with known active pulmonary metastasis. This was echoed by Marina et al. [19] for those with metastatic disease at diagnosis or in whom recurrence develops within 12 months, though whether routine imaging will improve outcomes is debatable [3]. Though surgery was previously advocated only in patients with solitary BM without systemic disease, more recently concurrent systemic disease has been suggested not to be a contraindication for SR $[15,16]$. Paulino et al. [17] reported RT to slow neurological deterioration in their cohort of pediatric patients. Unlike the majority of the authors, Flannery and colleagues [15] utilized Gamma Knife Stereotactic Radiosurgery (GKSRS) in their management and noted the modality to be a viable alternative to surgery in select cases.

As a commonly diagnosed musculoskeletal cancer in children and young adults, osteosarcoma, when metastatic, mainly spreads to the lungs and other bones and rarely to the brain. As such, it is difficult to form consensus guidelines on treatment once BM occurs. As many of these lesions are solitary, surgical excision has been the standard of care, with chemotherapy and RT for palliative measures.

3.1.2. Ewing's Sarcoma. Ewing's sarcoma is commonly seen in young adults and has a slight male predominance [2931]. Up to $80 \%$ of patients have subclinical metastases at time of presentation [29]. It comprises about $10 \%$ of primary malignant bone tumors and, like osteosarcoma, the lungs and distant skeletal tissues are common metastatic sites [31]. CNS metastases have been reported in $32-56 \%$ of cases, frequently a result of direct extension of bony metastases in close proximity, with BM making up $<1.8 \%$ of cases [32]. Extremity tumors generally have better prognosis than axial skeleton primaries, which are arduous to completely excise [31-33]. BM usually appears as part of systemic disease, with more than $85 \%$ having lung involvement [33].

Approximately 40 cases of ESBM have been described in the literature (Table 2) [2, 4, 9, 15-17, 22, 26, 30, 32, 34-38]. Average age of patients is approximately 20.9 years with $>65 \%$ males. The majority of BM is localized to the parietal lobe (16) $41 \%, 12(31 \%)$ to frontal lobe, and $5(13 \%)$ to temporoccipital lobes. IB was $23.2 \pm 27.1$ months (range: 0-115), with OS of $7.1 \pm 7.7$ months (range: 0-24) following detection. A combination of treatments was utilized in 17 patients (44\%), with 22 given chemotherapy (56\%). Reportedly, concomitant use of chemotherapy has increased long-term survival rates to $50-70 \%$ [29]. Specific treatments for BM included SR (25\%), WBRT (70\%), GKSRS (17.5\%), and conservative management (17\%). Primaries originated most commonly from lower extremities and were generally treated with RT and SR, with SR mostly utilized for axial skeleton tumors. 


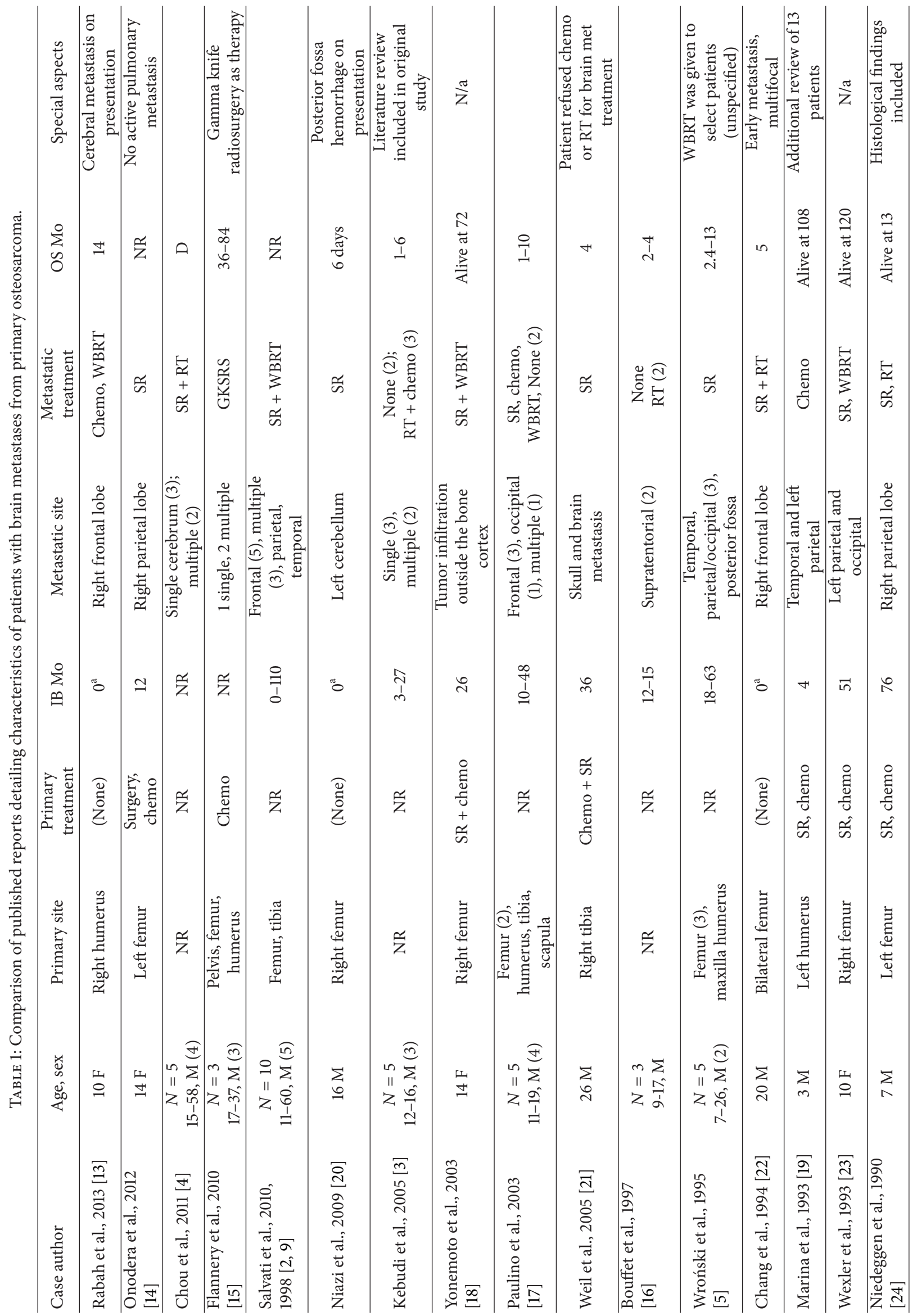




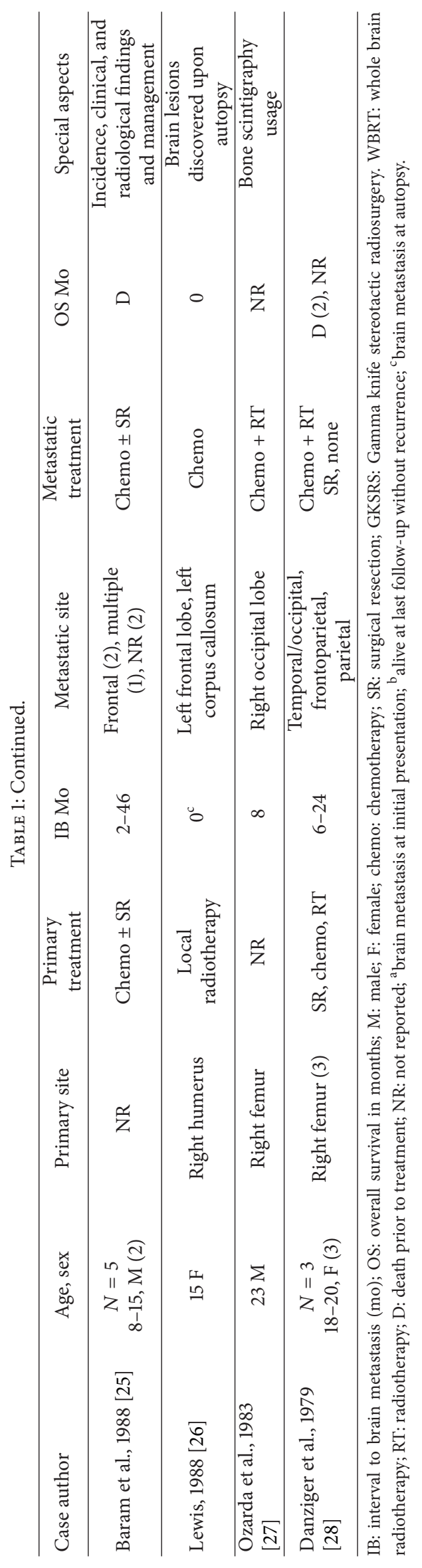




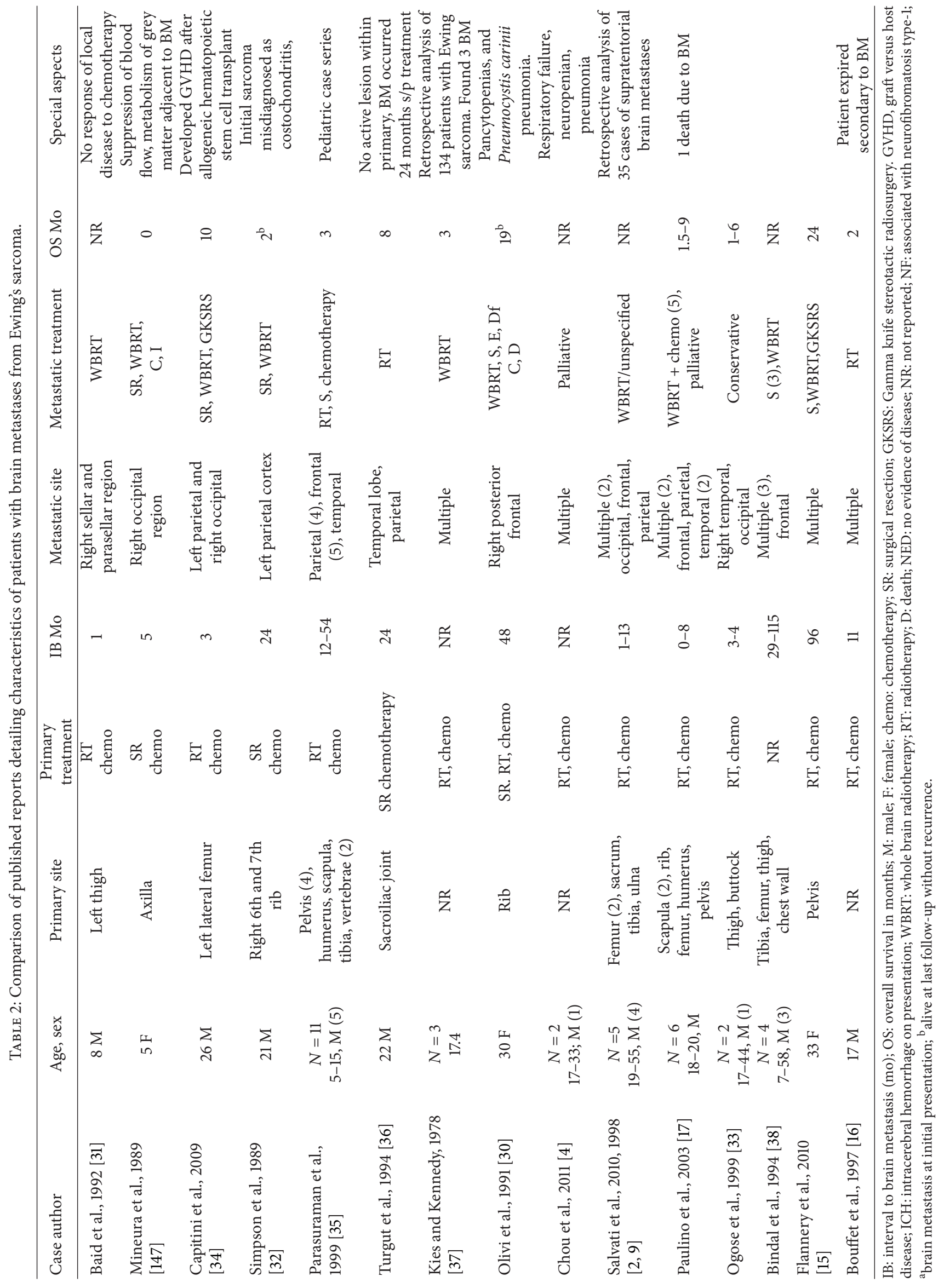


Overall, the appearance of BM signifies a poor prognostic outcome in patients with ES. The current increased frequency of CNS metastases has been linked to prolonged survival and alteration of host response following chemotherapy [26]. Moreover, recent therapies for metastatic ES have not substantially improved outcomes since the initiation of multidrug chemotherapy $[29,34]$. As one of the more common sarcomas metastasizing to the brain, it is hoped that future research may herald improved treatments.

3.1.3. Chondrosarcoma. Chondrosarcoma is a malignancy of mesenchyme that is a common primary bone tumor subsequent to osteosarcoma in frequency [39]. It has been classified based on histological appearance into slow growing, benign grade I to malignant grade III $[39,40]$. Distant metastases account for $10 \%$ of grade II and $71 \%$ of grade III [40], commonly occurring to lungs, other bones, and liver, resulting in a mere 5-year survival of 18\% [39]. Primary intracranial chondrosarcoma constitutes only $0.16 \%$ of all intracranial tumors. BM is exceedingly rare with only few documented cases [41]. Due to their sporadic nature, treatment options are extrapolated to other sarcomatous metastases.

Table 3 summarizes 12 previous chondrosarcoma patients with $\mathrm{BM}$ and shows an average age of 43.4 years, with 6 males and 6 females (50\%) [15, 39-48]. There were 2 children (age 18 and younger). Locations of the primary tumor were variable with 6 cases in the extremities (50\%) and most often treated with SR or amputation. BM was variable in location and occurred with an IB of $7.9 \pm 10.6$ years (range: $0.5-34$ ). OS was $16.9 \pm 16.7$ months (range: $2-44$ ) after BM. Most common treatments were SR in 4 cases $(33.3 \%)$ and GKSRS in 3 cases $(25 \%)$. Out of 6 cases in which cause of death was specified, 3 expired due to progressive neurologic disease and 3 expired from systemic disease.

Treatment with chemo- and radiotherapy has resulted in poor results, postulated due to the resistant extracellular matrix, low mitotic index, and sparse vascularization of cells $[39,42]$. As such, SR was utilized in most of the documented cases, though outcomes were dismal (Table 3). Flannery et al. [15] reported their experience with GKSRS in 21 patients with 60 sarcomatous BM, 2 from chondrosarcoma. Overall, the treatment resulted in a local tumor control rate of $88 \%$ with a median survival of 16 months following BM diagnosis. Tsutsumi et al. [40] also reported their experience with GKSRS in a 60-year-old male with chondrosarcoma BM that resulted in adequate control for over 10 months. Thus, GKSRS can be an effective option for these BM, especially small lesions.

Though chondrosarcoma accounts for $40 \%$ of primary bone cancers in adults [42], it rarely metastasizes to the brain but it can occur many years down the line. Once BM is diagnosed, it is usually treated with excisional surgery because of resistance to chemotherapy and radiotherapy [40]. More recently, GKSRS has shown promise to be an effective modality with long-term survival and improvement in quality of life.

3.1.4. Chordoma. Chordomas are rare, malignant tumors, which arise from the embryonic notochord [49-51]. Their indolent and progressive course often correlates with a poor prognosis in which they silently expand for years without any clinical symptoms $[49,50]$. They are quite uncommon, representing $4 \%$ of all malignant tumors of bone [51] and less than $1 \%$ of spine tumors [52]. Only about 70 metastasizing cases have been reported, characterizing chordomas as more locally invasive and less susceptible to distant metastasis [51]. There is a male predominance overall, though sacrococcygeal chordomas are more frequent in females [53]. No age preference is apparent, with children as young as 2 and adults in their $70 \mathrm{~s}$ afflicted [50]. The pediatric population, however, has been reported to harbor an aggressive form [52]. While the most common site of presentation is the caudal and cranial poles of the spine [54], chordomas are generally characterized into one of three principal clinicoanatomical categories: cranial, vertebral, and sacrococcygeal [49]. According to Hall and Clark, 50\% of patients have sacrum or coccyx involvement followed by $33 \%$ with clival involvement [51].

Inherently, chordomas destroy and replace bone in which they develop [55]. Until recently, it was thought that it spreads via direct extension, suggesting frank metastasis seldom occurs [54]. However, latest literature explores many cases of metastasis-especially in those presenting at sacrococcygeal sites. It is estimated $25-43 \%$ of sacrococcygeal chordomas will present with subsequent metastasis [51], most often to lymph nodes, liver, and lungs [54]. Metastasis presenting in the brain remains rare [51], and complete resection of the primary is vital for prevention and overall patient survival [53]. Table 3 outlines characteristics from published case reports on BM from chordoma $[49,51-56]$. Though SR and RT were initiated, most patients died shortly after brain involvement.

Metastasis from chordomas depends on many factors such as histology, mitotic activity, and treatment regimens [53]. Due to their rarity, optimal treatment remains with disappointing results. Surgical excision, while still the recommended treatment course for cure, is frequently not possible [55] though it does provide a palliative measure to reduce tumor load for subsequent chemotherapy [52]. The challenge continues as chordomas are also relatively radioand chemoresistant $[51,55]$. Further research is vital in order to discover satisfactory alternatives for appropriate therapy.

3.1.5. Fibroblastic and Fibrohistiocytic Tumors. Previously designated under "malignant fibrous tumors," these are rare malignancies characterized by pleomorphic, high-grade tumor cells with histiocytic, fibroblastic, and myofibroblastic features [57-59]. "Malignant fibrous histiocytoma (MFH)" has been renamed "undifferentiated pleomorphic sarcoma (UPS)" in the most recent WHO Classification of tumors of soft tissues and bone [58]. They rarely occur in children [59] and the predominant affected population is typically adult males [60]. Most common primary tumor sites are the extremities and retroperitoneum [57-60]. There is an exceedingly high reoccurrence rate, with some studies reporting as high as $44 \%$ [57]. The prognosis is generally poor with a $42 \%$ risk of distant metastasis $[57,61,62]$. Sites of 
TABLE 3: Comparison of published reports on patients with brain metastases from chondrosarcoma and chordoma.

\begin{tabular}{lccc}
\hline Case author & Age, sex & IB yr. & BM treatment \\
\hline & & Chondrosarcoma & GKSRS \\
Flannery et al., 2010 [15] & $14 \mathrm{M}, 56 \mathrm{M}$ & $0.5-1.3$ & Chemo for lung \\
Francés-Muñoz et al., 2012 [39] & $53 \mathrm{~F}$ & 10 & Chemo \\
Kawaguchi et al., 2012 [43] & $54 \mathrm{M}$ & 0.7 & SR \\
Jallu et al., 1992 [41] & $54 \mathrm{~F}$ & 0.7 & SR \\
Konishi et al., 1994 [44] & $72 \mathrm{~F}$ & 2 & SR \\
Reyaz and Ashraf, 2006 [45] & $34 \mathrm{~F}$ & 7 & - \\
Talerman, 1967 [46] & $26 \mathrm{~F}$ & - & D \\
Templeton et al., 1985 [47] & $15 \mathrm{M}$ & 34 & SR \\
Waga et al., 1972 [48] & $32 \mathrm{M}$ & 12 & NR \\
Tsutsumi et al., 2010 [40] & $60 \mathrm{M}$ & 4.4 & Chemo, GKSRS \\
Fox et al., 1968 [49] & $51 \mathrm{~F}$ & - & $\mathrm{D}$ \\
& & 32 & NR \\
Kamel et al., 2005 [53] & $12 \mathrm{M}$ & Chordoma & NR \\
Anderson and Meyers, 1968 [54] & $69 \mathrm{M}$ & 24 & $10+$ \\
Al-Adra et al., 2011 [52] & $29 \mathrm{M}$ & 2.5 & SR (gross total) \\
Morris and Rabinovitch, 1947 [56] & $41 \mathrm{M}$ & 36 & SR, WBRT \\
Fichardt and De Villiers, 1974 [55] & $59 \mathrm{M}$ & WBRT & SR \\
Higinbotham et al. 1967 [50] & $58 \mathrm{~F}$ & 18 & None (autopsy finding) \\
Mesgarzadeh et al., 2008 [57] & $27 \mathrm{~F}$ & None & 32 (alive) \\
\hline
\end{tabular}

Chemo: chemotherapy; D: death prior to treatment; F: female; GKSRS: Gamma knife stereotactic radiosurgery; IB: interval between diagnosis of brain metastasis from chondrosarcoma in years (yr); M: male; NR: not reported; OS: overall survival in months; Radio: radiotherapy; SR: surgical resection; WBRT: whole brain radiotherapy; ${ }^{a}$ diagnosed postmortem; ${ }^{\text {b }}$ brain metastasis diagnosed first; + : survival reported for at least the stated amount.

metastasis include lungs, liver, bone, and, very rarely, brain $[57,59,63,64]$.

Although these tumors can originate from either bone or soft tissue, defining the source is difficult [65]. Successful SR of the primary site with clear margins can be difficult; thus, local recurrence and metastasis are frequent. Both soft tissue and bone forms have the propensity for BM as the incidence at autopsy has been reported at $1.5 \%$ [64, 66]. Patients experiencing $\mathrm{BM}$ remain asymptomatic prior to events such as intracranial hemorrhage (ICH), which has been shown to occur $[61,67,68]$. Prognosis after detection of BM varies significantly and can be affected by the primary site, with soft tissue locations being more susceptible to multiple metastases [69].

As with other sarcomas, pulmonary metastasis is most common, with its detection increasing the risk of future BM $[66,68]$. Thus, both the primary site and the site(s) of metastasis are essential in accurate prognosis of patients. As shown in Table 4, the majority were MFH/UPS (17, $54.8 \%)$, with the rest being fibrosarcomas $(10,32.3 \%)$ and dermatofibrosarcomas (3, 9.7\%) [2, 5, 33, 38, 42, 57-73]. Multimodality treatment was utilized in many cases, including SR, chemotherapy, WBRT, and STRS. The IB was $33.2 \pm 41.0$ months ranging from 0 to 312 months. OS also was variable with a mean of $10.6 \pm 17.1$ months following $B M$, and a male predilection was observed (55.6\%).

Periodic imaging of the brain, the primary site, and the metastatic sites has been suggested to prolong life expectancy, though it remains controversial [64]. In addition, as these metastases tend to bleed, many patients often become symptomatic only after ICH, further reiterating the significance of routine screening in susceptible patients [61, 64, 67]. Similarly, the therapeutic range of chemotherapeutic agents must be monitored in an organ-specific manner for maximal efficacy [63]. Although cases of BM are uncommon, vigilance is warranted, particularly through frequent neurological examination in all patients and routine imaging in select cases [68].

3.2. Malignant Soft Tissue Tumors. The primary malignant soft tissue tumors (STS) discussed are also the most likely to metastasize to the brain: liposarcoma, rhabdomyosarcoma, malignant peripheral nerve sheath tumor, angiosarcoma, and alveolar soft part sarcoma.

3.2.1. Liposarcoma. Liposarcomas comprise about $10-20 \%$ of all STS [74-76]. While uncommon in children, liposarcoma is currently the second most frequent soft-tissue malignancy in adults [75]. Middle-aged and older adults are most susceptible [74], presenting most frequently deep within soft tissues of proximal extremities and retroperitoneum as large, bulky masses $[74,76,77]$. The incidence of BM after liposarcoma diagnosis is exceedingly rare and is most often preceded by pulmonary metastasis $[75,77]$.

Espat et al. [78] analyzed the cohort of 3829 patients from the Memorial Sloan Kettering Cancer Center between 1982 and 1999 who presented with STS. Forty patients (>1\%) 


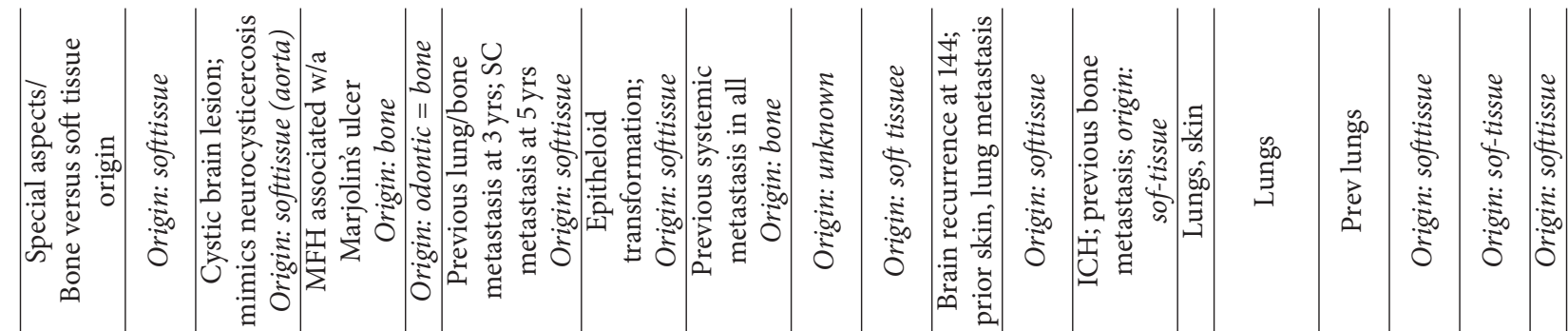

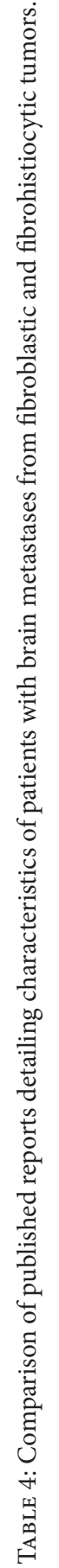

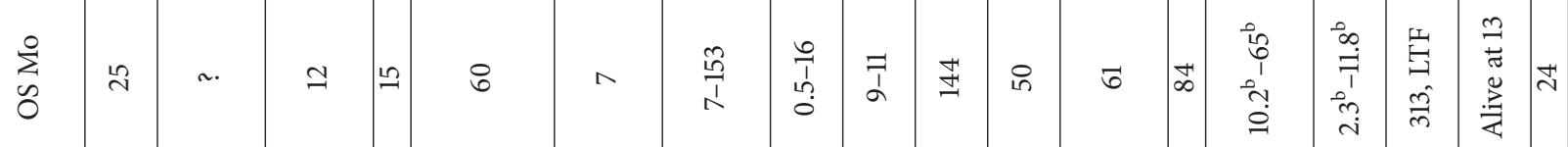

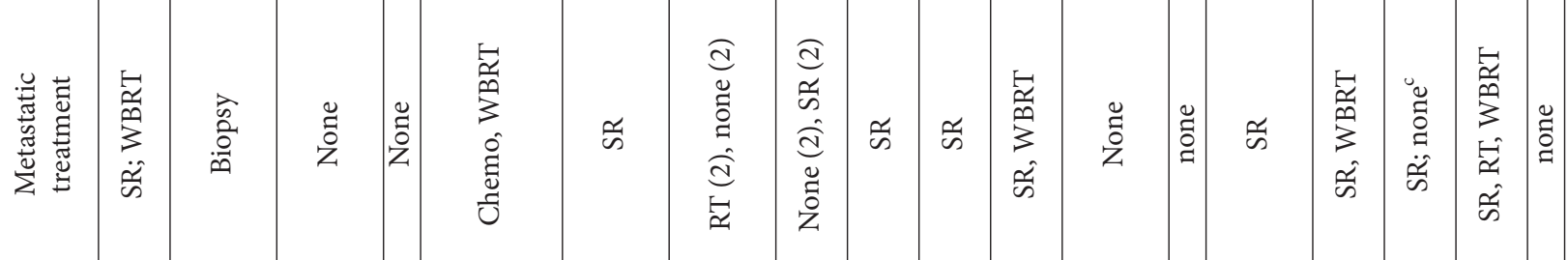

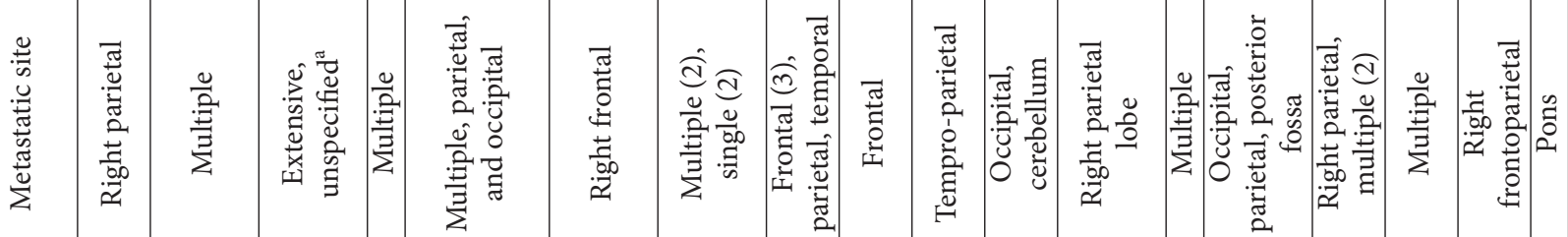

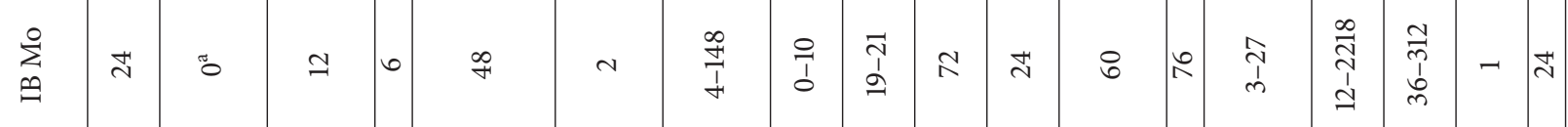

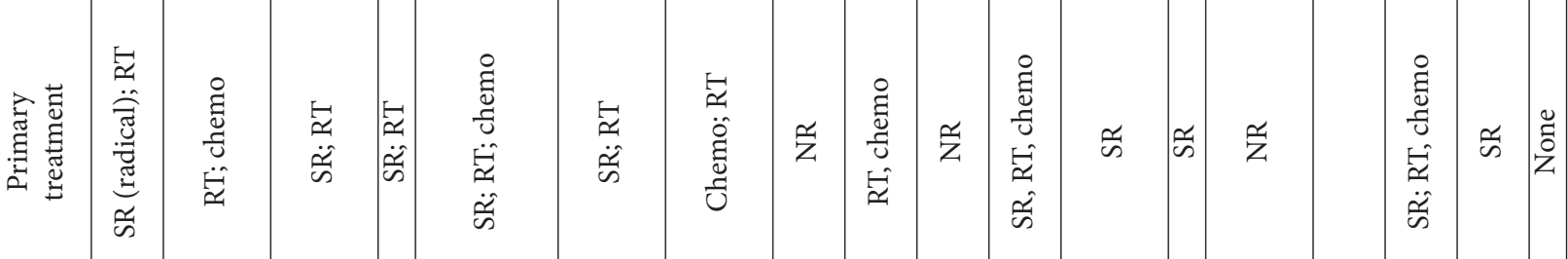

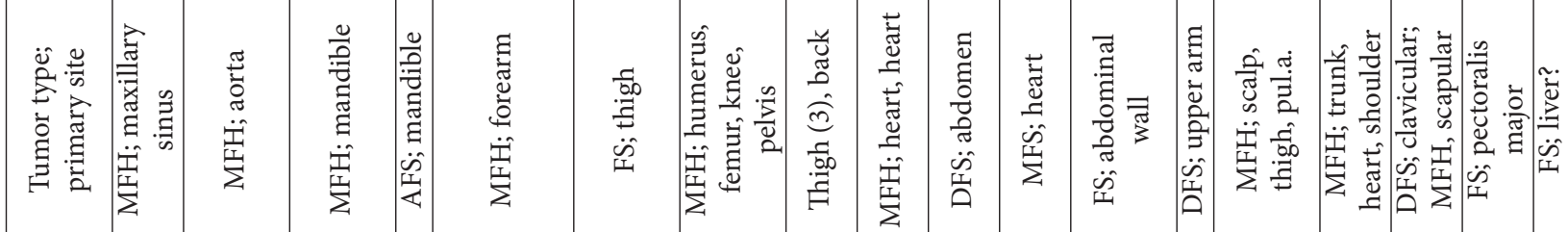

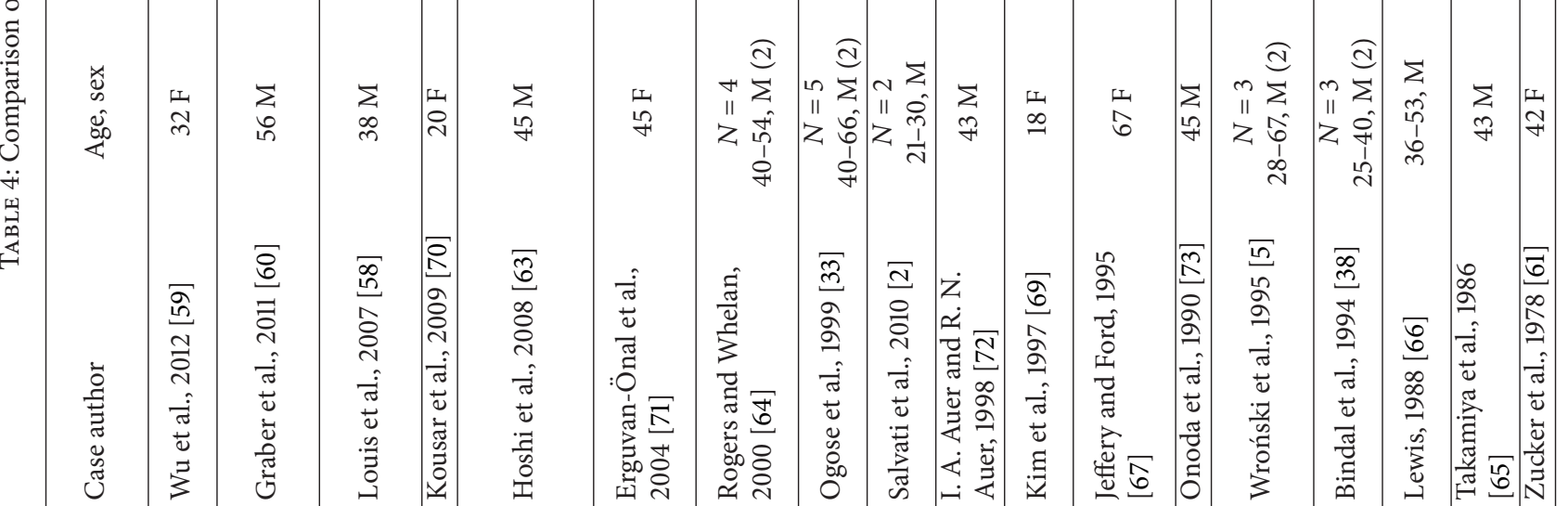




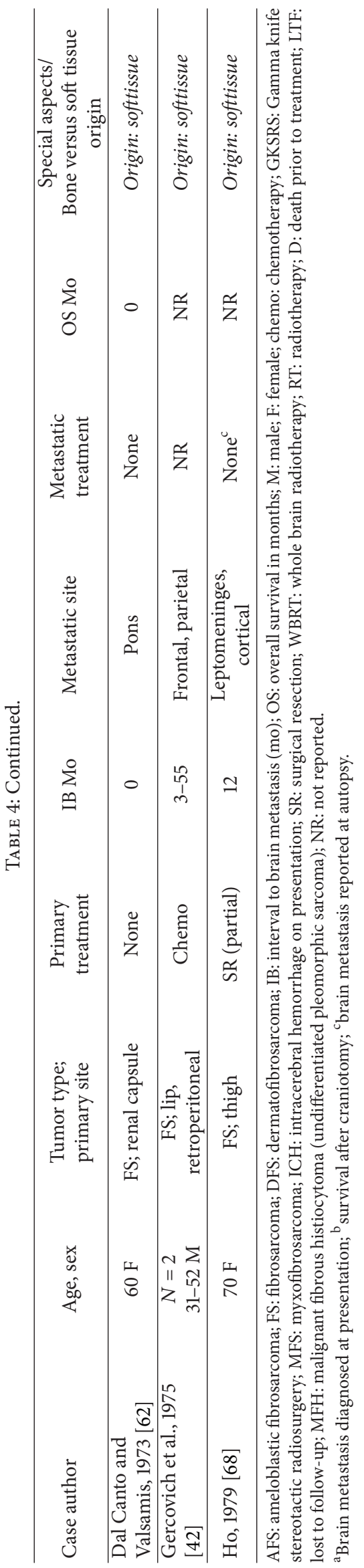


TABLE 5: Comparison of published reports detailing characteristics of patients with brain metastases from liposarcoma and rhabdomyosarcoma.

\begin{tabular}{|c|c|c|c|c|}
\hline Case author & Age, sex & IB yr. & BM treatment & OS Mo \\
\hline \multicolumn{5}{|c|}{ Rhabdomyosarcoma } \\
\hline Ahola et al., $1998[84]$ & $13 \mathrm{M}$ & 0.7 & SR & 14 \\
\hline Andersen-Ranberg and Helmer-Hansen, 1987 [83] & $19 \mathrm{M}$ & 0.5 & $\mathrm{NR}$ & $6+$ \\
\hline Flannery et al., 2010 [15] & $18 \mathrm{~F}$ & 5.0 & GKSRS, WBRT & 60 \\
\hline Ho, $1979[68]$ & $79 \mathrm{M}$ & - & $\mathrm{D}$ & - \\
\hline Kebudi et al., 2005 [3] & $11 \mathrm{M}$ & 0 & RT, Chemo & 3 \\
\hline Kleinert et al., 1985 [90] & $14 \mathrm{~F}$ & & $\mathrm{D}$ & 48 \\
\hline Noda et al., 1995 [91] & $2 \mathrm{M}$ & 0.5 & Chemo, RT & $32+$ \\
\hline Ogose et al., 1999 [33] & $7 \mathrm{~F}, 16 \mathrm{M}$ & $\mathrm{NR}, 0.2$ & Chemo, RT & 4,4 \\
\hline Osawa et al., 2011 [88] & $\begin{array}{c}N=3 \\
6-18, M(3)\end{array}$ & $1.1-12.2$ & SR, RT, Chemo & $21-207$ \\
\hline Paulino et al., 2003 [17] & $\begin{array}{c}N=8 \\
1.7-18, M(6)\end{array}$ & NR & WBRT, Chemo & $2-63$ \\
\hline Rodriguez-Galindo et al., 2001 [85] & $\begin{array}{c}N=5 \\
\text { Newborn, F }\end{array}$ & $0.1-1.1$ & $\mathrm{NR}$ & $1.5-24$ \\
\hline Salvati et al., 2010 [2] & $\begin{array}{c}N=2 \\
20-22, M(1)\end{array}$ & $0.2-0.3$ & SR & 12.8 \\
\hline \multicolumn{5}{|c|}{ Liposarcoma } \\
\hline Arepally et al., 1996 [76] & $56 \mathrm{M}$ & 312 & SR, WBRT & 324 \\
\hline Bailey et al., 2001 [74] & $54 \mathrm{~F}$ & 108 & SR, WBRT & Alive at 114 \\
\hline Can et al., 1993 [82] & $22 \mathrm{M}$ & 0 & none & \\
\hline Ferguson et al., 2006 [79] & $48 \mathrm{~F}$ & 276 & RT & 278 \\
\hline Fitzpatrick et al., 1999 [77] & $74 \mathrm{~F}$ & 24 & $\mathrm{SR}$ & Alive at 30 \\
\hline Haft et al., 1988 [80] & $52 \mathrm{~F}$ & 216 & SR (total), chemo & 228 \\
\hline Kumar and Teasdale, 2000 [81] & $73 \mathrm{~F}$ & 12 & SR & Alive at 12 \\
\hline Salvati et al., 2010 [2] & $48 \mathrm{M}$ & NR & SR & NR \\
\hline Utsunomiya et al., 1999 [75] & $44 \mathrm{M}$ & 72 & SR (subtotal) & 77 \\
\hline
\end{tabular}

IB: Interval to brain metastasis (mo); OS: overall survival in months; M: male; F: female; chemo: chemotherapy; SR: surgical resection; GKSRS: Gamma knife stereotactic radiosurgery; ICH: intracerebral hemorrhage on presentation; WBRT: whole brain radiotherapy; RT: radiotherapy; D: death prior to treatment;

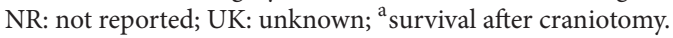

presented or developed STS BM, 5 (12.5\%) of which were liposarcoma patients-the second leading tumor causing STSBM in the cohort. Previous liposarcoma patients with BM are summarized in Table 5 [2, 74-77, 79-82]. Average patient age is 52.3 years. Parenchymal involvement included the temporoparietal region (44\%), frontal region (22\%), parafalcine $(11 \%)$, and skull base (11\%). The majority originated in the thigh and most patients received SR with or without chemotherapy and/or RT. The same is appreciated for the BM; SR was offered to most, combined with another modality for a few. IB was $127.5 \pm 124.0$ months and ranged from 0 to 313 months. Survival following BM is unfavorable even after SR, and the use of chemo- and radiotherapy is questionable at best.

As the lifespan of patients diagnosed with liposarcoma extends, the natural history of the disease leads to CNS metastases, which occurs in a large part after 10 years following original diagnosis $[2,76,79]$. Histologically, the degree of differentiation also contributes to the likelihood of metastasis [80]. Kumar and Teasdale [81] noted that the myxoid type liposarcomas have the lowest rates of BM while pleomorphic types have the highest $[75,82]$. Additionally, the origin of the liposarcoma dictates the extent of relapse $[74,78]$. Regardless of the available treatments, BM from liposarcomas is very unusual and should only be considered after relevant neurological findings $[2,74]$.

3.2.2. Rhabdomyosarcoma. Rhabdomyosarcoma (RMS) is a malignancy of striated muscle and one of the common STS in those under 20 years [83]. It usually arises from the head and neck, genitourinary system, and the extremities [84]. BM from RMS is exceedingly uncommon and is accompanied with neurologic symptoms in a minority of patients $[84,85]$. In his 1988 review, Lewis reported the detection of pulmonary metastases from RMS may indicate an increased risk of future BM [66]. Common metastatic sites are lungs, pleura, pancreas, and bones and occurs via blood or lymph flow $[83,86]$.

Vezeridis et al. [87] reviewed 242 patients with recurrent STS between 1960 and 1978; 68 (28.1\%) were metastatic RMS. In a Japanese study with 480 sarcoma patients [88], 2 of the 13 with metastatic RMS had BM (15.4\%). Parasuraman et 
al. [35] documented patients treated at St. Jude Children's Hospital from 1962 to 1998 with BM from RMS. Out of 419 patients, 10 developed BM (2.4\%). Median interval between primary tumor and diagnosis of $\mathrm{BM}$ was 1 year. The authors also showed that combined RT and chemotherapy prolong survival and improve prognosis, with an estimated 1-year survival of $30 \%$. Another study reported RT alone was inadequate while intensive chemotherapy and high dose RT to the primary site had a survival of $74 \%$ with a local control rate of $89 \%$ [89].

Like other sarcomas, multimodality treatment is instigated for those with BM from RMS [83]. Gasparini et al. [86] tracked two series of children with head and neck RMS and intracranial involvement. They found that CNS prophylactic chemotherapy and higher doses of RT resulted in a better ability to achieve persistent local tumor control. As shown in Table 5 , previously reported cases of RMS with BM $[2,3,15,17$, $33,35,68,83-85,88,90,91$ ] have an average age of 12.0 years, with majority being males $(21,56.8 \%)$. Most were children (89.2\%) including 5 neonates. Thirteen tumors originated from the extremities (35.1\%) and treatment of the primary was multimodal. BM were in variable locations including 7 parietal (18.9\%), 7 frontal (18.9\%), and 5 cerebellar (13.5\%). IB is $1.7 \pm 2.3$ years (range: $0-12.2$ ) and OS was $15.6 \pm 16.0$ months (range: 0-207). Treatments included WBRT in 20 cases $(54.1 \%)$, chemotherapy in 18 (48.6\%), and SR or GKSRS in $8(21.6 \%)$. Cause of death was neurologic deterioration in $12(32.4 \%)$ and systemic disease in $10(27.0 \%)$, with the rest alive at last followup.

RMS is a common STS affecting young patients, and it has been known to metastasize to different organs and tissues. Patients with a history of metastasis have a significant risk of future BM [3]. Surgical treatment for select patients can result in long-term survival $[87,88]$, and increasing doses and volume of RT have been shown to prolong survival [86]. Overall, a combined modality approach is advocated.

3.2.3. Malignant Peripheral Nerve Sheath Tumors. A number of entities are synonymous with malignant peripheral nerve sheath tumors (MPNST) including neurofibrosarcoma, neurogenic sarcoma, and malignant schwannoma [92]. MPNST usually arise from nerves of extremities and trunk or from preexisting neurofibromas and account for less than $10 \%$ of all STS $[93,94]$. Uncommon in the general population with an incidence of $0.001 \%$, it is much more common in those with neurofibromatosis type 1 (NF-1) [93]. Surgery is the primary treatment of MPNST with the aim of radical en bloc SR $[93,95]$, followed by RT for local control whether clear surgical margins are achieved or not [93, 96, 97]. Due to its infrequency, outcomes are difficult to determine, though reportedly poorer than other sarcomas [92, 98]. The incidence of $\mathrm{BM}$ is exceptionally rare with only 21 documented cases (Table 6) [15, 92-94, 99-115].

According to Table 6, MPNST patients with BM have an average age of 36.6 years, with $2 / 3$ males and $4(19.0 \%)$ children. Location of the primary neoplasm varies and its treatment almost always involves surgical resection (SR). The frontal lobe was the most common location for BM (28.6\%) and the infratentorial region was involved in 6 cases (28.6\%).
IB occurred at $32.4 \pm 54.5$ months (range: $0-180$ ) and OS was $9.9 \pm 15.2$ months (range: 1-16) following BM. Additionally, at mean follow-up of 42.6 months, 2 patients (10.5\%) remained alive. Seven (33.3\%) had a history of NF-1. The majority of cases expired due to widely metastatic disease.

Aggressive SR followed by WBRT is the basis of treatment for BM. However, because of the limited pool of patients, there are cases surviving for many months without treatment and others dying over a short period after aggressive intervention [93, 94, 99]. Tilgner et al. [92] reported on a patient with 2 BM treated by WBRT and SR of only one of the lesions. Interestingly, there was local control of both lesions at 14 months, highlighting the importance of WBRT for MPNST BM. The importance of RT should not be underestimated, as one reported case with cerebellar metastasis was treated with en bloc SR without RT only to have local recurrence 4 months later [94]. Another report presented GKRS as a viable option for multiple BM with excellent initial and long-term response [100]. Park et al. [101] noted the tumor's tendency to bleed on presentation and our review builds on this as 5 (23.8\%) of all reviewed cases had ICH on presentation (Table 6). Cerebrospinal fluid dissemination is hypothesized as the likely route [102], though hematogenous metastasis, cannot be excluded.

MPNST is a very aggressive cancer associated with high recurrence and metastatic potential. Prognosis is generally poor and worse with metastasis [102, 103, 116]. It does have the potential for BM, though reported mainly in case reports. A greater potential for BM may exist from spinal tumors (Table 6). Treatment should involve aggressive SR combined with RT. Overall, the appearance of BM signifies an impending poor outcome in patients with MPNST. More cases and studies should be reported to help establish a suitable therapeutic approach.

3.2.4. Angiosarcoma. Angiosarcoma is an exceedingly rare malignancy, which arises from endothelial cells of the vasculature. The least common among vascular tumors, angiosarcoma has a prevalence of $<1 \%$ of all sarcomas [117, 118]. Certain described risk factors include vinyl chloride exposure, chronic lymphedema, and arsenic exposure [119]. They occur mainly in the head, face, liver, skin, and other soft tissues. Most skin and soft tissue angiosarcomas are treated with SR along with adjuvant chemotherapy or RT [118]. BM is unusual, with only a few reported cases (Table 6).

Current understanding of the metastatic behavior of angiosarcomas is limited. Of reported cases with BM, the often involved primary site is the heart [120]. Though, in a retrospective analysis of primary neoplasms of the heart only $2 \%$ were angiosarcomas [119]. Review of literature also showed 6 cases of metastatic splenic angiosarcoma, 2 with BM. Table $6[32,117-129]$ shows an average age corresponding to 42.3 years with $70 \%$ males. Origin was overrepresented by thoracic or abdominal angiosarcomas (66.6\%). Treatment involved SR $93.3 \%$ of the time (14/15) and localized RT in only $2 / 15$ cases $(13.3 \%$ ). IB was approximately $16.4 \pm 21.7$ (range: $0-72$ ) and OS was $4.8 \pm 7.3$ months, following conservative palliative treatment in 7 (46.6\%) and SR in another 7 (46.6\%). Metastases were reported mostly in the parietal (30.7\%) 
TABLE 6: Comparison of published reports detailing characteristics of patients with brain metastases from malignant peripheral nerve sheath tumor (MPNST) and angiosarcoma.

\begin{tabular}{|c|c|c|c|c|}
\hline Case author & Age, sex & IB yr. & BM treatment & OS Mo \\
\hline \multicolumn{5}{|c|}{ Malignant peripheral nerve sheath tumors } \\
\hline Xu et al., 2012 [93] & $8 \mathrm{M}$ & 14 & (None) & 16 \\
\hline Flannery et al., 2010 [15] & $34 \mathrm{~F}$ & 36 & SR, WBRT, GKSRS & 48 \\
\hline Tilgner et al., 2007 [92] & $60 \mathrm{M}$ & $0^{\mathrm{a}}$ & SR, WBRT & Alive at 14 \\
\hline Park et al., 2007 [101] & $21 \mathrm{M}$ & $0^{\mathrm{a}}$ & SR, WBRT, Chemo & 16 \\
\hline van Eck and Horstmann, 2006 [100] & $83 \mathrm{M}$ & 108 & SR, GKSRS & 122 \\
\hline Matyja et al., 2004 [94] & $33 \mathrm{M}$ & $\sim 56$ & SR & $\sim 60$ \\
\hline Yone et al., 2004 [104] & $4 \mathrm{M}$ & 7 & WBRT & 21 \\
\hline Oishi et al., 2000 [102] & $48 \mathrm{M}$ & 61 & SR (en bloc) & NR \\
\hline Maschke et al., 1999 [105] & $17 \mathrm{~F}$ & $0^{\mathrm{a}}$ & SR & NR \\
\hline Probst-Cousin et al., 1997 [106] & $19 \mathrm{~F}$ & 156 & None & 157 \\
\hline Haisa et al., 1996 [103] & $58 \mathrm{~F}$ & 180 & SR (en bloc) & 181 \\
\hline Fenzi et al., 1995 [99] & $45 \mathrm{~F}$ & 5 & None & 18 \\
\hline Seppälä and Haltia, 1993 [107] & $13 \mathrm{M}$ & 2 & None & 2 \\
\hline D’Angelo et al., 1991 [115] & $68 \mathrm{~F}$ & 24 & SR (en bloc) & 36 \\
\hline Valdueza et al., 1991 [108] & $47 \mathrm{M}$ & $\sim 13$ & None & 18 \\
\hline Cras et al., 1990 [109] & $46 \mathrm{~F}$ & 0 & None & 0 \\
\hline Hirose et al., 1989 [110] & $53 \mathrm{M}$ & 15 & SR (en bloc), chemo & Alive at $20^{\mathrm{b}}$ \\
\hline Hasegawa et al., 1984 [111] & $51 \mathrm{M}$ & 2 & Biopsies & 3 \\
\hline Macaulay, 1978 [112] & $18 \mathrm{M}$ & 2 & None & 2 \\
\hline White Jr., 1971 [113] & $20 \mathrm{M}$ & NR & SR, radiation & 7 \\
\hline D’Agostino et al., 1963 [114] & $22 \mathrm{~F}$ & NR & NR & 68 \\
\hline \multicolumn{5}{|c|}{ Angiosarcoma } \\
\hline Liassides et al., 2004 [119] & $24 \mathrm{~F}$ & 3 & Palliative & 6 \\
\hline Eguchi et al., 2002 [123] & $64 \mathrm{M}$ & 19 & Palliative & 0 \\
\hline Chami et al., 1994 [118] & $59 \mathrm{M}$ & NR & Palliative & NR \\
\hline Vaquero et al., 1990 [124] & $30 \mathrm{M}$ & 4 & SR & 6 \\
\hline Kuratsu et al., 1991 [117] & $17 \mathrm{M}$ & - & SR & 12 \\
\hline Haft et al., 1988 [80] & $31 \mathrm{~F}$ & - & WBRT & NR \\
\hline Akutsu et al., 2004 [125] & $53 \mathrm{M}$ & 2 & SR & 6 \\
\hline Ellegala et al., 2002 [121] & $76 \mathrm{M}$ & 24 & SR & 2 \\
\hline Søndenaa et al., 1993 [126] & $73 \mathrm{~F}$ & 3 & Palliative & 3 \\
\hline Gallo et al., 2001 [127] & $33 \mathrm{M}$ & 12 & SR & 0 \\
\hline Hassane et al., 2010 [128] & $48 \mathrm{M}$ & 3 & Palliative & 0 \\
\hline Simpson et al., 1989 [32] & $21 \mathrm{M}$ & 24 & SR, WBRT & $26^{\mathrm{b}}$ \\
\hline Angrish et al., 1979 [120] & $38 \mathrm{M}$ & 3 & Palliative & 0 \\
\hline Plotnik et al., 2008 [122] & $61 \mathrm{~F}$ & 60 & SR & NR \\
\hline Chaudhuri et al., 1980 [129] & $31 \mathrm{~F}$ & 72 & SR, WBRT & 2 \\
\hline Macaulay, 1978 [112] & $18 \mathrm{M}$ & 2 & Palliative & 0 \\
\hline
\end{tabular}

IB: interval to brain metastasis (mo); OS: overall survival in months; M: male; F: female; chemo: chemotherapy; SR: surgical resection; GKSRS: Gamma knife stereotactic radiosurgery; ICH: intracerebral hemorrhage on presentation; WBRT: whole brain radiotherapy; RT: radiotherapy; D: death prior to treatment; NR: not reported; NF: associated with neurofibromatosis type-1; ${ }^{\mathrm{a}}$ brain metastasis at initial presentation.; ${ }^{\mathrm{b}}$ alive at last follow-up without recurrence.

or frontal lobe (23\%). Most expired secondary to systemic complications.

Overall, the prognosis of angiosarcoma is grim. Typical 5 -year survival is $12 \%$, with metastases and reoccurrence typically occurring within the first 2 years [118]. Prognosis varies highly with the primary site [122], and surgical resection is often difficult because of hefty tumor size at presentation [119]. Once angiosarcoma has metastasized, especially to the brain, mean survival is decreased to 2-6 months, signifying a bleak outcome.
3.2.5. Alveolar Soft Part Sarcoma. Alveolar soft part sarcomas (ASPS) account for a small percentage of STS at roughly $1 \%$ $[88,89]$. In contrast to bone-part tumors, ASPS is a soft-part tumor that presents mainly in muscle and deep soft tissue of the thigh or leg [130-133]. A malignancy found in younger patients, those diagnosed are mostly below the age of 40 years $[130,131,133,134]$. While it metastasizes to lung and bone, unlike other sarcomas, it has a predisposition towards BM with estimates of 15 to $30 \%$ in those with stage IV disease $[1,135]$. On the other hand, ASPS patients have been reported 
to have greater oncological control with better relapse-free survival [1]; even though $25 \%$ of patients have metastasis at presentation, overall survival is comparatively high at 10-12 years $[136,137]$.

Portera et al. [134] studied a large cohort of 74 patients with ASPS. The majority (65\%) presented with Stage IV disease and BM (19\%) was only present in those with other metastases, particularly lung. Eight (88.9\%) of the 9 patients with BM developed neurological symptoms, and imaging performed in those without such symptoms did not reveal occult BM. Resistance to conventional chemotherapy was noted and overall survival was 40 months. Daigeler et al. [130] described similar result in their small series and recommended SR followed by RT for both the primary and resectable metastases and found tumor size at presentation to not influence long-term results.

The literature is abundant with reports of BM from ASPS. Table 7 presents a summary of cases from published series $[2,4,5,15,38,130,134,138,139]$. The IB ranged from 1 to 156 months, roughly averaging 29 months. Patient's age was approximately 30 years, without a remarkable predilection to any one of the sexes. OS ranged significantly (1-36 years), with a mean between 3 and 4 years [130]. Five-year survival reportedly ranges between 59 and 67\% [133]. Longterm survivors have been known to exhibit spontaneous regression phenomenon, in which there is partial or complete disappearance of the malignancy in absence of traditional treatment [131].

Neurosurgical resection can be favorable and may increase long-term survival $[1,132,133,135]$. A surgical advantage may exist with ASPS when compared to other sarcomas. There is little evidence to support routine brain imaging without metastatic disease at other sites. Chemotherapy has not been found to be helpful, as there is frequently lack of response. Even though ASPS has a larger predisposition for BM, patients with ASPS BM generally have a better prognosis than other bone and soft tissue malignancies [1].

3.2.6. Other Soft Tissue Sarcomas. Malignant histiocytomas (undifferentiated pleomorphic sarcomas) and fibrosarcomas originating from the soft tissues are covered under the fibroblastic and fibrohistiocytic tumors section. Also, Table 4 includes previous such cases originating from soft tissues with BM. Brain metastases from leiomyosarcomas are frequently reported; however, they rarely originate from musculoskeletal structures. For instance, Salvati et al. [2] have reported 7 cases of brain metastasis from leiomyosarcoma. Most of these cases had their primary site as the uterus, with others reporting ovarian and gastrointestinal origins [3]. Others have reported BM from gastrointestinal origins such as GIST [140].

\section{Discussion}

Previous landmark studies on the treatment of brain metastases have shown efficacy in surgical resection and postoperative WBRT $[141,142]$, as well as stereotactic radiosurgery [143]. Most such studies have focused on common sources of BM such as lung, breast, and genitourinary cancers. Here, via a thorough literature search, we presented an up-to-date and comprehensive review of the current literature regarding BM from bone and STS. The literature on this topic is limited to case reports and case series. Consequently, variable results are reported with regard to prevalence, management, and outcomes. A few points are noteworthy, however.

Generally, BM from these cancers is very infrequent, most commonly occurring in Ewing's sarcoma, fibroblastic/fibrohistiocytic tumors, and osteosarcoma. Pediatric patients are more likely to have RMS. Though ASPS commonly metastasizes to the brain, it is a much rare cancer and thus accounts for a lesser proportion. Many of the larger studies suggest a slight preponderance in males (52-60\%) $[2,5,9,38,144]$. It is a disease of younger patients with an average age range between 12 and 52 years and a mean of 32.5. The most important factor in developing BM in many of these cancers is a history of pulmonary metastasis. Most common locations for metastasis follow the anterior circulation, hence, the cerebral hemispheres. Additionally, they tend to be single lesions $(>60 \%)$, rather than multiple [2]. The point at which BM occurs in these patients is unpredictable, with many found at presentation and others developing many months or even years later. An estimate in the range of 20-30 months is suggested by the literature $[2,5,9,38,144]$, with most being detected before 24 months (osteosarcoma, Ewing sarcoma, chordoma, angiosarcoma, and rhabdomyosarcoma), some at 24-36 months (fibroblastic/fibrohistiocytic tumors, malignant peripheral nerve sheath tumors, and alveolar soft part sarcoma) and a few after $>36$ months (chondrosarcoma, liposarcoma). Liposarcoma and chondrosarcoma have repeatedly been reported to develop BM many years following initial diagnosis.

Comprehensive neurological evaluation and imaging should be performed on development of suspicious neurological signs or symptoms. Clinical presentation of BM is characterized by rapid onset of neurological symptoms, such as paresthesias, visual field defects, and headache. Generally, routine neuroimaging studies without these indications are not warranted because of the rarity of BM and because they almost always result in signs and symptoms if they are present though it has been suggested to screen patients with osteosarcoma and MFT with extensive disease, especially if there is a short disease free interval $[18,19,64]$.

The extent of systemic disease and Karnofsky Performance Scale (KPS), as well as sarcoma histotype are important factors in determining patient outcomes. The presurgical KPS gives an overall clinical picture, and a score above $60-70$ has been cited as a good prognostic indicator associated with higher median survival $[2,5,9,38,144]$. In addition, repeatedly throughout the literature the presence and degree of extracranial involvement have been cited as a very important consideration in management of decision making and predictor of survival. As many of these cancers tend to be radio- and chemoresistant $[1,2]$, their management becomes challenging. Surgical resection of their BM can improve neurological function and is a safe, feasible option in select patients with a favorable KPS and controlled systemic disease. This intervention should be also considered for solitary brain lesions with sequelae and/or mass effect. 


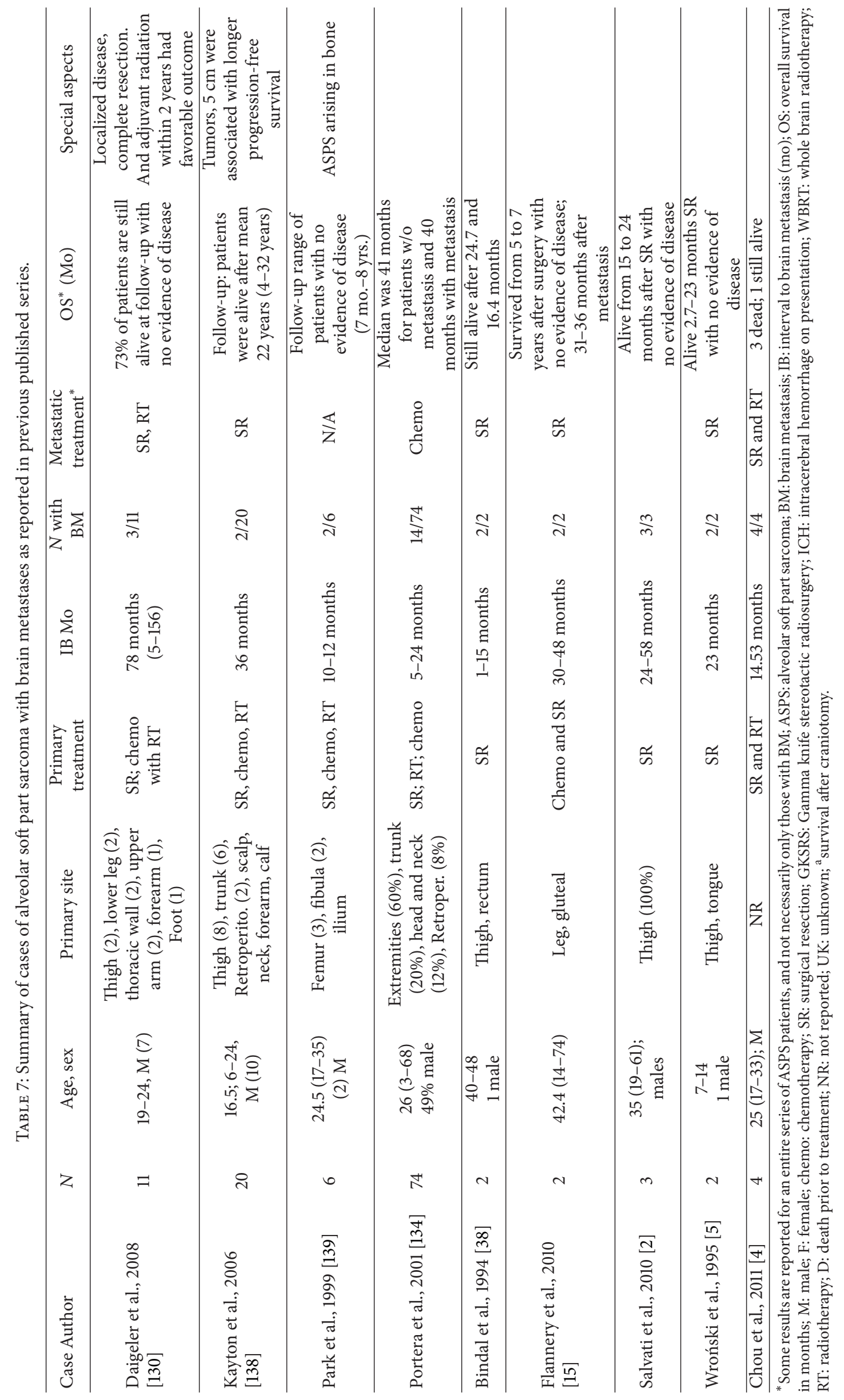


Enhancements in surgical methods, anatomical navigation tools, brain mapping techniques, and awake neurosurgery have made it possible to excise multiple lesions in previously considered inoperable locations $[1,2]$.

While SR has been suggested to lead to improved outcomes $[1,2,5,9,38,144]$, it is not an option for many patients. When the number of metastatic foci is beyond a certain point (2-3), STRS should be considered and can provide similar or even better results [15]. This modality should be considered in those with less than 6 lesions, each $<3-3.5 \mathrm{~cm}$ in diameter [15]. Palliative treatment with WBRT and chemotherapy should be provided to those with many BMs and concurrent systemic disease, keeping in mind that an aggressive approach with multimodality treatment with or without SR can be judiciously given to certain patients as stated above. More recent studies have highlighted the potential of new chemotherapeutic and radiotherapeutic adjuvants $[145,146]$. Overall mean survival is estimated at $7-$ 16 months, with the majority surviving $<12$ months (Ewing's sarcoma, liposarcoma, fibroblastic/fibrohistiocytic tumors, malignant peripheral nerve sheath tumors, angiosarcoma, and chordomas) and a minority $>12$ months (osteosarcoma, chondrosarcoma, rhabdomyosarcoma, and alveolar soft part sarcoma). Bone and soft tissue BM in children is more atypical and is even more problematic to make meaningful conclusions on management and outcomes.

\section{Conclusion}

Brain metastasis in bone and soft tissue cancers usually occurs late in the malignancy. As most of the data in the literature is from case reports and case series utilizing heterogeneous treatments, it is difficult to discern the best therapeutic strategy. Prolonged survival and an adequate quality of life are achievable in a small, select population of patients. While such a survival advantage may exist for those given an aggressive treatment course involving surgical resection, it should be reserved for those with a favorable preoperative performance status and minimal systemic disease. Future large prospective studies can help give more insight on this uncommon, yet growing group of brain metastases. Overall, the occurrence of BM in patients with bone and soft tissue cancers is a poor prognostic sign that suggests late stage disease.

\section{Conflict of Interests}

The authors declare that there is no conflict of interests regarding the publication of this paper.

\section{References}

[1] B. D. Fox, A. Patel, D. Suki, and G. Rao, "Surgical management of metastatic sarcoma to the brain: clinical article," Journal of Neurosurgery, vol. 110, no. 1, pp. 181-186, 2009.

[2] M. Salvati, A. D'Elia, A. Frati, and A. Santoro, "Sarcoma metastatic to the brain: a series of 35 cases and considerations from 27 years of experience," Journal of Neuro-Oncology, vol. 98, no. 3, pp. 373-377, 2010.
[3] R. Kebudi, I. Ayan, O. Görgün, F. Y. Ağaoğlu, S. Vural, and E. Darendeliler, "Brain metastasis in pediatric extracranial solid tumors: survey and literature review," Journal of NeuroOncology, vol. 71, no. 1, pp. 43-48, 2005.

[4] Y.-S. Chou, C.-Y. Liu, W.-M. Chen et al., "Brain, the last fortress of sarcoma: similar dismal outcome but discrepancy of timing of brain metastasis in bone and soft tissue sarcoma," Journal of Surgical Oncology, vol. 104, no. 7, pp. 765-770, 2011.

[5] M. Wroński, E. Arbit, M. Burt, G. Perino, J. H. Galicich, and M. F. Brennan, "Resection of brain metastases from sarcoma," Annals of Surgical Oncology, vol. 2, no. 5, pp. 392-399, 1995.

[6] S. Postovsky, S. Ash, I. N. Ramu et al., "Central nervous system involvement in children with sarcoma," Oncology, vol. 65, no. 2, pp. 118-124, 2003.

[7] M. Betzler, "Klassifikation der Knochentumoren verbindet Kliniker und Pathologen," Klinikarzt, vol. 12, pp. 959-971, 1983.

[8] D. C. Dahlin and K. K. Unni, "Osteosarcoma of bone and its important recognizable varieties," American Journal of Surgical Pathology, vol. 1, no. 1, pp. 61-72, 1977.

[9] M. Salvati, L. Cervoni, R. Caruso, F. M. Gagliardi, and R. Delfini, "Sarcoma metastatic to the brain: a series of 15 cases," Surgical Neurology, vol. 49, no. 4, pp. 441-444, 1998.

[10] M. P. Link, M. C. Gebhardt, and P. A. Meyers, "Osteosarcoma," in Principles \& Practice of Pediatric Oncology, pp. 1075-1113, Lippincott Williams \& Wilkins, 5th edition, 2005.

[11] M. Deutsch, S. Orlando, and M. Wollman, "Radiotherapy for metastases to the brain in children," Medical and Pediatric Oncology, vol. 39, no. 1, pp. 60-62, 2002.

[12] S. K. Singh, N. E. Leeds, and L. E. Ginsberg, "MR imaging of leptomeningeal metastases: comparison of three sequences," American Journal of Neuroradiology, vol. 23, no. 5, pp. 817-821, 2002.

[13] F. Rabah, N. Al-Mashaikhi, I. Beshlawi et al., "Brain is not always the last fortress, osteosarcoma with large brain metastasis," Journal of Pediatric Hematology/Oncology, vol. 35, no. 2, pp. e91e93, 2013.

[14] H. Onodera, Y. Yoshida, Y. Sakakibara et al., "A case of intracerebral metastasis in osteosarcoma without active pulmonary metastasis," British Journal of Neurosurgery, vol. 26, no. 1, pp. 91-93, 2012.

[15] T. Flannery, H. Kano, A. Niranjan et al., "Gamma knife radiosurgery as a therapeutic strategy for intracranial sarcomatous metastases," International Journal of Radiation Oncology Biology Physics, vol. 76, no. 2, pp. 513-519, 2010.

[16] E. Bouffet, N. Doumi, P. Thiesse et al., "Brain metastases in children with solid tumors," Cancer, vol. 79, no. 2, pp. 403-410, 1997.

[17] A. C. Paulino, T. X. Nguyen, and J. L. Barker Jr., "Brain metastasis in children with sarcoma, neuroblastoma, and Wilms' tumor," International Journal of Radiation Oncology Biology Physics, vol. 57, no. 1, pp. 177-183, 2003.

[18] T. Yonemoto, S.-I. Tatezaki, T. Ishii, K. Osato, and T. Takenouchi, "Longterm survival after surgical removal of solitary brain metastasis from osteosarcoma," International Journal of Clinical Oncology, vol. 8, no. 5, pp. 340-342, 2003.

[19] N. M. Marina, C. B. Pratt, S. J. Shema, T. Brooks, B. Rao, and W. H. Meyer, "Brain metastases in osteosarcoma. Report of a longterm survivor and review of the St. Jude Children's Research Hospital experience," Cancer, vol. 71, no. 11, pp. 3656-3660, 1993. 
[20] T. N. Niazi, C. Forester, Z. Afify, and J. Riva-Cambrin, "Osteosarcoma presenting as hemorrhagic cerebellar metastasis," Child's Nervous System, vol. 25, no. 12, pp. 1643-1647, 2009.

[21] R. J. Weil, R. R. Lonser, and M. M. Quezado, "CNS manifestations of malignancies: case 2. Skull and brain metastasis from tibial osteosarcoma," Journal of Clinical Oncology, vol. 23, no. 18, pp. 4226-4229, 2005.

[22] J. W. Chang, S. L. Howng, Z. M. Sun, T. H. Kuo, and C. C. Duh, "An unusual intracranial metastasis of osteosarcoma," Kaohsiung Journal of Medical Sciences, vol. 10, no. 12, pp. 700704, 1994.

[23] L. H. Wexler, T. F. DeLaney, S. Saris, and M. E. Horowitz, "Longterm survival after central nervous system relapse in a patient with osteosarcoma," Cancer, vol. 72, no. 4, pp. 1203-1208, 1993.

[24] A. Niedeggen, J. Weis, R. Mertens, J. Rother, and J. Brocheler, "Unusually long survival time after resection and irradiation of a brain metastasis from osteosarcoma," Neurosurgical Review, vol. 13, no. 3, pp. 247-252, 1990.

[25] T. Z. Baram, P. Van Tassel, and N. A. Jaffe, "Brain metastases in osteosarcoma: incidence, clinical and neuroradiological findings and management options," Journal of Neuro-Oncology, vol. 6, no. 1, pp. 47-52, 1988.

[26] A. J. Lewis, "Sarcoma metastatic to the brain," Cancer, vol. 61, no. 3, pp. 593-601, 1988.

[27] A. T. Ozarda, J. R. Legaspi, and T. P. Haynie, "Detection of a brain metastasis from osteosarcoma with $99 \mathrm{mTc}$-methylene diphosphonate bone scanning," European Journal of Nuclear Medicine, vol. 8, no. 12, pp. 552-554, 1983.

[28] J. Danziger, S. Wallace, S. F. Handel, and L. A. DeSantos, "Metastatic osteogenic sarcoma to the brain," Cancer, vol. 43, no. 2, pp. 707-710, 1979.

[29] A. O. Karosas, "Ewing's sarcoma," American Journal of HealthSystem Pharmacy, vol. 67, no. 19, pp. 1599-1605, 2010.

[30] A. Olivi, R. C. Donehower, R. B. Mann, and H. Brem, "Solitary, isolated metastasis from Ewing's sarcoma to the brain: case report," Surgical Neurology, vol. 35, no. 3, pp. 239-243, 1991.

[31] B. L. Baid, R. K. Tanwar, S. De et al., "Intracranial metastasis in Ewing's sarcoma," The Indian Journal of Pediatrics, vol. 59, no. 1, pp. 125-127, 1992.

[32] R. K. Simpson Jr., J. M. Bruner, and M. E. Leavens, "Metastatic Ewing's sarcoma to the brain: case report and review of treatment," Surgical Neurology, vol. 31, no. 3, pp. 234-238, 1989.

[33] A. Ogose, T. Morita, T. Hotta et al., "Brain metastases in musculoskeletal sarcomas," Japanese Journal of Clinical Oncology, vol. 29, no. 5, pp. 245-247, 1999.

[34] C. M. Capitini, J. Derdak, M. S. Hughes et al., "Unusual sites of extraskeletal metastases of ewing sarcoma after allogeneic hematopoietic stem cell transplantation," Journal of Pediatric Hematology/Oncology, vol. 31, no. 2, pp. 142-144, 2009.

[35] S. Parasuraman, J. Langston, B. N. Rao et al., "Brain metastases in pediatric Ewing sarcoma and rhabdomyosarcoma: the St. Jude Children's Research Hospital experience," Journal of Pediatric Hematology/Oncology, vol. 21, no. 5, pp. 370-377, 1999.

[36] M. Turgut, A. Colak, and O. Gürçay, "Multiple intracranial metastases with skull and scalp involvement in Ewing's sarcoma," Central African Journal of Medicine, vol. 40, no. 4, pp. 104-106, 1994.

[37] M. S. Kies and P. S. Kennedy, "Central nervous system involvement in Ewing's sarcoma," Annals of Internal Medicine, vol. 89, no. 2, pp. 226-227, 1978.
[38] R. K. Bindal, R. E. Sawaya, M. E. Leavens et al., "Sarcoma metastatic to the brain: results of surgical treatment," Neurosurgery, vol. 35, no. 2, pp. 185-191, 1994.

[39] E. Francés-Muñoz, R. Gallego-Pinazo, D. Pardo-López, and M. Diaz-Llopis, "Choroidal metastasis from chondrosarcoma," Graefe's Archive for Clinical and Experimental Ophthalmology, vol. 250, no. 6, pp. 949-951, 2012.

[40] S. Tsutsumi, Y. Yasumoto, H. Oizumi, and M. Ito, "Chondrosarcoma with atypical clinical presentation treated by gamma knife radiosurgery for multiple brain metastases," Neurologia MedicoChirurgica, vol. 50, no. 6, pp. 502-505, 2010.

[41] A. Jallu, I. Kanaan, and S. Agarwal, "Metastatic chondrosarcoma of the brain: a case report," Annals of Saudi Medicine, vol. 12, no. 3, pp. 307-308, 1992.

[42] F. G. Gercovich, M. A. Luna, and J. A. Gottlieb, "Increased incidence of cerebral metastases in sarcoma patients with prolonged survival from chemotherapy. Report of cases of leiomyosarcoma and chondrosarcoma," Cancer, vol. 36, no. 5, pp. 1843-1851, 1975.

[43] T. Kawaguchi, Y. Yamanouchi, Y. Numa et al., "A case of metastatic brain tumor causing multifocal cerebral embolism," Brain Tumor Pathology, vol. 29, no. 1, pp. 63-67, 2012.

[44] H. Konishi, K. Isetani, T. Satoh, S. Fukuda, T. Kodama, and K. Kashima, "A case of metastatic chondrosarcoma of the stomach," Journal of Gastroenterology, vol. 29, no. 4, pp. 495500, 1994.

[45] N. Reyaz and M. Ashraf, "Intracranial extra-skeletal mesenchymal chondrosarcoma," Journal of Ayub Medical College, vol. 18, no. 2, pp. 86-87, 2006.

[46] A. Talerman, "Chondrosarcoma with long-delayed metastasis of unusual distribution," The Journal of Pathology and Bacteriology, vol. 93, no. 1, pp. 348-350, 1967.

[47] P. A. Templeton, F. E. Gellad, and C. Wood, "Computed tomography of metastatic chondrosarcoma to the brain," Journal of Computer Assisted Tomography, vol. 9, no. 4, pp. 829-830, 1985.

[48] S. Waga, M. Matsushima, K. Ando, and S. Morii, "Intracranial chondrosarcoma with extracranial metastases. Case report," Journal of Neurosurgery, vol. 36, no. 6, pp. 790-794, 1972.

[49] J. E. Fox, J. G. Batsakis, and L. R. Owano, "Unusual manifestations of chordoma. A report of two cases," Journal of Bone and Joint Surgery A, vol. 50, no. 8, pp. 1618-1628, 1968.

[50] N. L. Higinbotham, R. F. Phillips, H. W. Farr, and H. O. Hustu, "Chordoma. Thirty-five-year study at Memorial Hospital," Cancer, vol. 20, no. 11, pp. 1841-1850, 1967.

[51] W. A. Hall and H. B. Clark, "Sacrococcygeal chordoma metastatic to the brain with review of the literature," Journal of Neuro-Oncology, vol. 25, no. 2, pp. 155-159, 1995.

[52] D. Al-Adra, A. Bennett, R. Gill, and G. Lees, "Pediatric metastatic sacrococcygeal chordoma treated with surgery," European Journal of Pediatric Surgery, vol. 21, no. 3, pp. 196-198, 2011.

[53] M. H. Kamel, C. Lim, M. Kelleher, K. Aquilina, C. Keohane, and G. Kaar, "Intracranial metastasis from a sacrococcygeal chordoma: case report," Journal of Neurosurgery, vol. 102, no. 4, pp. 730-732, 2005.

[54] W. B. Anderson and H. I. Meyers, "Multicentric chordoma. Report of a case," Cancer, vol. 21, no. 1, pp. 126-128, 1968.

[55] T. Fichardt and P. C. De Villiers, "Chordoma," South African Medical Journal, vol. 48, no. 10, pp. 383-391, 1974.

[56] A. A. Morris and R. Rabinovitch, "Malignant chordoma of the lumbar region, report of a case with autopsy, comment 
on unusual metastases to the brain, lungs, pancreas, sacrum and axillary and iliac lymph nodes," Archives of Neurology \& Psychiatry, vol. 57, no. 5, pp. 547-564, 1947.

[57] A. H. Mesgarzadeh, R. M. Z. Farahani, and N. Treister, "Malignant fibrous histiocytoma of the mandible in the context of a traumatic Marjolin's ulcer," Journal of Tissue Viability, vol. 17, no. 2, pp. 38-43, 2008.

[58] "WHO classification of tumours of the central nervous system," in World Health Organization Classification of Tumours, D. N. Louis, H. Ohgaki, O. D. Wiestler, and W. K. Cavanee, Eds., International Agency for Reasearch on Cancer, Lyon, France, 4th edition, 2007.

[59] T.-H. Wu, C.-W. Shih, J.-S. Huang, C.-H. Wang, and K.-Y. Yeh, "Unusual hematogenous brain metastasis in malignant fibrous histiocytoma of the maxillary sinus," International Journal of Clinical Oncology, vol. 17, no. 1, pp. 69-74, 2012.

[60] J. J. Graber, A. Nayar, and D. Zagzag, "Metastatic cerebral malignant fibrous histiocytoma masquerading as neurocysticercosis," Journal of Neuro-Oncology, vol. 105, no. 2, pp. 437-439, 2011.

[61] D. K. Zucker, R. Katz, A. Koto, and D. S. Horoupian, "Sarcomas metastatic to the brain: case report of a metastatic fibrosarcoma, and review of literature," Surgical Neurology, vol. 9, no. 3, pp. 177-180, 1978.

[62] M. Dal Canto and M. P. Valsamis, "Fibrosarcoma metastatic to the brain. An unusual case," Archives of Pathology and Laboratory Medicine, vol. 96, no. 2, pp. 108-110, 1973.

[63] M. Hoshi, M. Takami, and M. Ieguchi, "Pleomorphic malignant fibrous histiocytoma: response of bone, lung, and brain metastases to chemotherapy," Radiation Medicine, vol. 26, no. 8, pp. 499-503, 2008.

[64] S. J. Rogers and J. S. Whelan, "Cerebral metastases from malignant fibrous histiocytoma of bone," Sarcoma, vol. 4, no. 3, pp. 125-128, 2000.

[65] Y. Takamiya, S. Toya, and Y. Iizaka, "Intracranial metastasis of soft tissue fibrosarcoma. Case report," Neurologia MedicoChirurgica, vol. 26, no. 1, pp. 54-57, 1986.

[66] A. J. Lewis, "Sarcoma metastatic to the brain," Cancer, vol. 61, no. 3, pp. 593-601, 1988.

[67] D. R. Jeffery and C. C. Ford, "Fibrosarcomatous metastasis the central nervous system with overt hemorrhage: case report and review of the literature," Journal of the Neurological Sciences, vol. 134, no. 1-2, pp. 207-209, 1995.

[68] K. L. Ho, "Sarcoma metastatic to the central nervous system: report of three cases and review of the literature," Neurosurgery, vol. 5, no. 1, pp. 44-48, 1979.

[69] D. G. Kim, S. Y. Lee, S. K. Chung, S. K. Park, Y. K. Chun, and J. G. Chi, "Brain metastasis from myxofibrosarcoma of the heart," Acta Neurochirurgica, vol. 139, no. 1, pp. 88-89, 1997.

[70] A. Kousar, M. M. Hosein, Z. Ahmed, and K. Minhas, "Rapid sarcomatous transformation of an ameloblastic fibroma of the mandible: case report and literature review," Oral Surgery, Oral Medicine, Oral Pathology, Oral Radiology and Endodontology, vol. 108, no. 3, pp. e80-e85, 2009.

[71] R. Erguvan-Önal, Ç. Önal, A. Gürlek, A. Alkan, H. Ş. Erkal, and B. Mizrak, "Metastatic fibrosarcoma of the brain: transformation from conventional to epithelioid form. Case report," Neurologia Medico-Chirurgica, vol. 44, no. 9, pp. 497-501, 2004.

[72] I. A. Auer and R. N. Auer, "Metastatic dermatofibrosarcoma protuberans mimicking meningioma," Clinical Neuropathology, vol. 17, no. 4, pp. 190-193, 1998.
[73] N. Onoda, Y. Tsutsumi, K. Kakudo et al., "Pigmented dermatofibrosarcoma protuberans (Bednar tumor). An autopsy case with systemic metastasis," Acta Pathologica Japonica, vol. 40, no. 12, pp. 935-940, 1990.

[74] S. C. Bailey, B. Bailey, N. T. Smith, P. Van Tassel, and C. R. Thomas Jr., "Brain metastasis from a primary liposarcoma of the digit: case report," American Journal of Clinical Oncology, vol. 24, no. 1, pp. 81-84, 2001.

[75] A. Utsunomiya, H. Kinouchi, T. Kayama, and T. Yoshimoto, "Distant metastasis of liposarcoma to the dura and skull: a case report," British Journal of Neurosurgery, vol. 13, no. 5, pp. 520$522,1999$.

[76] G. Arepally, L. C. Kenyon, and E. Lavi, "Late onset of isolated central nervous system metastasis of liposarcoma-a case report," American Journal of Clinical Oncology, vol. 19, no. 4, pp. 351-355, 1996.

[77] M. O. Fitzpatrick, K. Tan, and D. Doyle, "Metastatic liposarcoma of the brain: case report and review of the literature," British Journal of Neurosurgery, vol. 13, no. 4, pp. 411-412, 1999.

[78] N. J. Espat, M. Bilsky, J. J. Lewis, D. Leung, and M. F. Brennan, "Soft tissue sarcoma brain metastases: prevalence in a cohort of 3829 patients," Cancer, vol. 94, no. 10, pp. 2706-2711, 2002.

[79] M. Ferguson, W. Stewart, F. Cowie, and J. White, "Late-onset meningeal metastases in liposarcoma: a case report and review of the literature," Sarcoma, vol. 2006, Article ID 23039, 3 pages, 2006.

[80] H. Haft, G. C. Wang, and B. P. O’Neill, "Metastatic liposarcoma of the brain with response to chemotherapy: case report," Neurosurgery, vol. 23, no. 6, pp. 777-780, 1988.

[81] S. Kumar and E. Teasdale, "Metastatic liposarcoma of the brain," Clinical Radiology, vol. 55, no. 5, pp. 406-408, 2000.

[82] C. Can, F. Arpaci, B. Celasun, O. Gunhan, and R. Finci, "Primary pericardial liposarcoma presenting with cardiac tamponade and multiple organ metastases," Chest, vol. 103, no. 1, p. 328, 1993.

[83] F. Andersen-Ranberg and H. B. Helmer-Hansen, "Alveolar rhabdomyosarcoma with cerebral and cerebellar metastases and subarachnoidal bleeding: a case report," Clinical Neuropathology, vol. 6, no. 3, pp. 120-122, 1987.

[84] D. T. Ahola, J. M. Provenzale, and D. C. Longee, "Metastatic rhabdomyosarcoma presenting as intracranial hemorrhage: imaging findings," European Journal of Radiology, vol. 26, no. 3, pp. 241-243, 1998.

[85] C. Rodriguez-Galindo, D. A. Hill, O. Onyekwere et al., "Neonatal alveolar rhabdomyosarcoma with skin and brain metastases," Cancer, vol. 92, no. 6, pp. 1613-1620, 2001.

[86] M. Gasparini, F. Lombardi, and C. Lovati, "Childhood rhabdomyosarcoma with meningeal extension: results of combined therapy including central nervous system prophylaxis," American Journal of Clinical Oncology, vol. 6, no. 4, pp. 393-398, 1983.

[87] M. P. Vezeridis, R. Moore, and C. P. Karakousis, "Metastatic patterns in soft-tissue sarcomas," Archives of Surgery, vol. 118, no. 8, pp. 915-918, 1983.

[88] S.-I. Osawa, T. Kumabe, R. Saito et al., "Infratentorial brain metastases of pediatric non-epithelial malignant tumors: three case reports," Brain Tumor Pathology, vol. 28, no. 2, pp. 167-174, 2011.

[89] J. M. Gerson, N. Jaffe, M. H. Donaldson, and M. Tefft, "Meningeal seeding from rhabdomyosarcoma of the head and neck with base of the skull invasion: recognition of the clinical evolution and suggestions for management," Medical and Pediatric Oncology, vol. 5, pp. 137-144, 1978. 
[90] R. Kleinert, A. Beham, and G. Rosanelli, "Alveolar rhabdomyosarcoma in a young female patient metastasizing to the brain," Acta Neuropathologica, vol. 67, no. 3-4, pp. 341-344, 1985.

[91] T. Noda, T. Todani, Y. Watanabe et al., "Alveolar rhabdomyosarcoma of the lung in a child," Journal of Pediatric Surgery, vol. 30, no. 11, pp. 1607-1608, 1995.

[92] J. Tilgner, K. Müller, N. Ghanem, J. Lutterbach, and J. Vesper, "Brain metastases as primary manifestation of a melanocytic malignant peripheral nerve sheath tumor in a 60-year-old man," BMC Neurology, vol. 7, article 2, 2007.

[93] Q. Xu, B. Xing, X. Huang, R. Wang, Y. Li, and Z. Yang, "Primary malignant peripheral nerve sheath tumor of the cauda equina with metastasis to the brain in a child: case report and literature review," Spine Journal, vol. 12, no. 4, pp. e7-e13, 2012.

[94] E. Matyja, E. Nagańska, R. Górski, and M. Zabek, "Multiple brain metastases from malignant peripheral nerve sheath tumour (MPNST)," Folia Neuropathologica, vol. 42, no. 1, pp. 43-48, 2004.

[95] G. Gupta and A. Maniker, "Malignant peripheral nerve sheath tumors," Neurosurgical Focus, vol. 22, no. 6, p. E12, 2007.

[96] B. S. Ducatman, B. W. Scheithauer, and D. G. Piepgras, "Malignant peripheral nerve sheath tumors. A clinicopathologic study of 120 cases," Cancer, vol. 57, no. 10, pp. 2006-2021, 1986.

[97] F. K. Storm, F. R. Eilber, J. Mirra, and D. L. Morton, "Neurofibrosarcoma," Cancer, vol. 45, no. 1, pp. 126-129, 1980.

[98] L. Angelov, A. Davis, B. O'Sullivan, R. Bell, and A. Guha, "Neurogenic sarcomas: experience at the University of Toronto," Neurosurgery, vol. 43, no. 1, pp. 56-65, 1998.

[99] F. Fenzi, G. Moretto, G. Zamboni, M. G. Passarin, and N. Rizzuto, "Brain metastases from post-radiation malignant peripheral nerve sheath tumour," The Italian Journal of Neurological Sciences, vol. 16, no. 6, pp. 495-498, 1995.

[100] A. T. C. J. van Eck and G. A. Horstmann, "Gamma Knife surgery for multiple brain metastases from a malignant schwannoma of the penis," Journal of Neurosurgery, vol. 105, supplement, pp. 238-240, 2006.

[101] S.-K. Park, H.-J. Yi, S.-S. Paik, Y.-J. Kim, Y. Ko, and S.-J. Oh, "Metastasizing malignant peripheral nerve sheath tumor initially presenting as intracerebral hemorrhage. Case report and review of the literature," Surgical Neurology, vol. 68, no. 1, pp. 79-84, 2007.

[102] H. Oishi, K. Ishii, K. Bandou, H. Ashida, and M. Abe, "Malignant schwannoma metastasizing to the parenchyma of the brain-case report," Neurologia Medico-Chirurgica, vol. 40, no. 2, pp. 116-119, 2000.

[103] T. Haisa, T. Kondo, N. Shinoura, T. Hara, and M. Nasu, "Malignant schwannoma metastasizing to the dura mater-case report," Neurologia Medico-Chirurgica, vol. 36, no. 7, pp. 462$465,1996$.

[104] K. Yone, K. Ijiri, K. Hayashi et al., "Primary malignant peripheral nerve sheath tumor of the cauda equina in a child case report," Spinal Cord, vol. 42, no. 3, pp. 199-203, 2004.

[105] M. Maschke, O. Kastrup, V. Reinhardt, and M. Keidel, "Multiple intracerebral metastases of a 17-year-old girl with previously diagnosed neurofibromatosis type I," Clinical Neuropathology, vol. 18, no. 1, pp. 42-44, 1999.

[106] S. Probst-Cousin, M. Schaus, B. Feldt, N. Al-Dandashi, and F. Gullotta, "Malignant peripheral nerve sheath tumor with extensive miliary metastases: a case report," General and Diagnostic Pathology, vol. 142, no. 5-6, pp. 357-360, 1997.
[107] M. T. Seppälä and M. J. J. Haltia, "Spinal malignant nervesheath tumor or cellular schwannoma? A striking difference in prognosis," Journal of Neurosurgery, vol. 79, no. 4, pp. 528-532, 1993.

[108] J. M. Valdueza, C. Hagel, M. Westphal, M. Hansel, and H.-D. Herrmann, "Primary spinal malignant schwannoma: clinical, histological and cytogenetic findings," Neurosurgical Review, vol. 14, no. 4, pp. 283-291, 1991.

[109] P. Cras, C. Ceuterick-De Groote, M. Van Vyve, A. Vercruyssen, and J.-J. Martin, "Malignant pigmented spinal nerve root schwannoma metastasizing in the brain and viscera," Clinical Neuropathology, vol. 9, no. 6, pp. 290-294, 1990.

[110] T. Hirose, M. Sumitomo, E. Kudo et al., "Malignant peripheral nerve sheath tumor (MPNST) showing perineurial cell differentiation," American Journal of Surgical Pathology, vol. 13, no. 7, pp. 613-620, 1989.

[111] M. Hasegawa, H. Tanaka, and I. Watanabe, "Malignant schwannoma and follicular thyroid carcinoma associated with von Recklinghausen's disease," Journal of Laryngology and Otology, vol. 98, no. 10, pp. 1057-1061, 1984.

[112] R. A. A. Macaulay, "Neurofibrosarcoma of the radial nerve in von Recklinghausen's disease with metastatic angiosarcoma," Journal of Neurology Neurosurgery and Psychiatry, vol. 41, no. 5, pp. 474-478, 1978.

[113] H. R. White Jr., "Survival in malignant schwannoma. An 18-year study," Cancer, vol. 27, no. 3, pp. 720-729, 1971.

[114] A. N. D’Agostino, E. H. Soule, and R. H. Miller, "Sarcomas of the peripheral nerves and somatic soft tissues associated with multiple neurofibromatosis (von Recklinghausen's disease)," Cancer, vol. 16, pp. 1015-1027, 1963.

[115] V. D’Angelo, G. Casadei, and L. Bizzozero, "Cerebral metastasis from an epithelioid malignant schwannoma: case report," Neurosurgery, vol. 29, no. 6, pp. 906-909, 1991.

[116] P. P. Sordillo, L. Helson, and S. I. Hajdu, "Malignant schwannoma-clinical characteristics, survival, and response to therapy," Cancer, vol. 47, no. 10, pp. 2503-2509, 1981.

[117] J.-I. Kuratsu, H. Seto, M. Kochi, Y. Itoyama, S. Uemura, and Y. Ushio, "Metastatic angiosarcoma of the brain," Surgical Neurology, vol. 35, no. 4, pp. 305-309, 1991.

[118] T. N. Chami, L. E. Ratner, J. Henneberry, D. P. Smith, G. Hill, and P. O. Katz, "Angiosarcoma of the small intestine: a case report and literature review," American Journal of Gastroenterology, vol. 89, no. 5, pp. 797-800, 1994.

[119] C. Liassides, M. Katsamaga, G. Deretzi, V. Koutsimanis, and G. Zacharakis, "Cerebral metastasis from heart angiosarcoma presenting as multiple hematomas," Journal of Neuroimaging, vol. 14, no. 1, pp. 71-73, 2004.

[120] K. Angrish, S. C. Manchanda, S. K. Shankar, and P. Chopra, "Primary angiosarcoma of the heart," Japanese Heart Journal, vol. 20, no. 3, pp. 375-380, 1979.

[121] D. B. Ellegala, C. Kligora, S. Vandenberg, A. Dumont, and M. E. Shaffrey, "Intracranial metastasis of a primary scalp angiosarcoma: case illustration," Journal of Neurosurgery, vol. 97, no. 3, p. 725, 2002.

[122] A. N. Plotnik, P. Schweder, A. Tsui, and B. Kavar, "Splenic angiosarcoma metastasis to the brain," Journal of Clinical Neuroscience, vol. 15, no. 8, pp. 927-929, 2008.

[123] K. Eguchi, S. Ishi, H. Sugiura, and K. Noga, "Angiosarcoma of the chest wall in a patient with fibrous dysplasia," European Journal of Cardio-Thoracic Surgery, vol. 22, no. 4, pp. 654-655, 2002. 
[124] J. Vaquero, R. Martinez, S. Coca, S. Oya, and R. Burgos, "Cerebral metastasis from angiosarcoma of the heart: case report," Journal of Neurosurgery, vol. 73, no. 4, pp. 633-635, 1990.

[125] H. Akutsu, K. Tsuboi, N. Sakamoto, T. Nose, S. Honma, and T. Jikuya, "Cerebral metastasis from angiosarcoma of the aortic wall: case report," Surgical Neurology, vol. 61, no. 1, pp. 68-71, 2004.

[126] K. Søndenaa, R. Heikkilä, A. Nysted et al., "Diagnosis of brain metastases from a primary hemangiosarcoma of the spleen with magnetic resonance imaging," Cancer, vol. 71, no. 1, pp. 138-141, 1993.

[127] P. Gallo, L. I. Dini, G. A. Saraiva, I. Sonda, and G. Isolan, "Hemorrhage in cerebral metastasis from angiosarcoma of the heart: case report," Arquivos de Neuro-Psiquiatria, vol. 59, no. 3, pp. 793-796, 2001.

[128] S. Hassane, E. Fouad, I. Said et al., "Orbital metastatic angiosarcoma," Korean Journal of Ophthalmology, vol. 24, no. 6, pp. 364366, 2010.

[129] B. Chaudhuri, S. G. Ronan, and J. R. Manaligod, "Angiosarcoma arising in a plexiform neurofibroma. A case report," Cancer, vol. 46, no. 3, pp. 605-610, 1980.

[130] A. Daigeler, C. Kuhnen, J. Hauser et al., "Alveolar soft part sarcoma: clinicopathological findings in a series of 11 cases," World Journal of Surgical Oncology, vol. 6, article 71, 2008.

[131] M. N. BaniHani and A. R. A. Al Manasra, "Spontaneous regression in alveolar soft part sarcoma: case report and literature review," World Journal of Surgical Oncology, vol. 7, article 53, 2009.

[132] J. C. Fanburg-Smith, M. Miettinen, A. L. Folpe, S. W. Weiss, and E. L. B. Childers, "Lingual alveolar soft part sarcoma; 14 cases: novel clinical and morphological observations," Histopathology, vol. 45 , no. 5, pp. 526-537, 2004.

[133] C.-H. Wang, N. Lee, and L.-S. Lee, "Successful treatment for solitary brain metastasis from alveolar soft part sarcoma," Journal of Neuro-Oncology, vol. 25, no. 2, pp. 161-166, 1995.

[134] C. A. Portera Jr., V. Ho, S. R. Patel et al., "Alveolar soft part sarcoma: clinical course and patterns of metastasis in 70 patients treated at a single institution," Cancer, vol. 91, no. 3, pp. 585-591, 2001.

[135] T. H. Shin, Y. J. Jung, O. L. Kim, and M. S. Kim, "Alveolar soft part sarcoma metastasized to both the skull and the brain," Journal of Korean Neurosurgical Society, vol. 52, no. 1, pp. 55-57, 2012.

[136] G. S. S. Kumar, G. Chacko, A. G. Chacko, and V. Rajshekhar, "Alveolar soft-part sarcoma presenting with multiple intracranial metastases," Neurology India, vol. 52, no. 2, pp. 257-258, 2004.

[137] J. R. Perry, J. M. Bilbao, M. Salcman, and R. Sawaya, "Metastatic alveolar soft part sarcoma presenting as a dural-based cerebral mass," Neurosurgery, vol. 34, no. 1, pp. 168-170, 1994.

[138] M. L. Kayton, P. Meyers, L. H. Wexler, W. L. Gerald, and M. P. LaQuaglia, "Clinical presentation, treatment, and outcome of alveolar soft part sarcoma in children, adolescents, and young adults," Journal of Pediatric Surgery, vol. 41, no. 1, pp. 187-193, 2006.

[139] Y.-K. Park, K. K. Unni, Y. W. Kim et al., "Primary alveolar soft part sarcoma of bone," Histopathology, vol. 35, no. 5, pp. 411-417, 1999.

[140] D. Drazin, K. Spitler, S. Jeswani, A. Shirzadi, S. Bannykh, and C. Patil, "Multiple intracranial metastases from a gastric gastrointestinal stromal tumor," Journal of Clinical Neuroscience, vol. 20, no. 3, pp. 471-473, 2012.
[141] R. A. Patchell, P. A. Tibbs, J. W. Walsh et al., "A randomized trial of surgery in the treatment of single metastases to the brain," New England Journal of Medicine, vol. 322, no. 8, pp. 494-500, 1990.

[142] R. A. Patchell, P. A. Tibbs, W. F. Regine et al., "Postoperative radiotherapy in the treatment of single metastases to the brain: a randomized trial," Journal of the American Medical Association, vol. 280, no. 17, pp. 1485-1489, 1998.

[143] D. W. Andrews, C. B. Scott, P. W. Sperduto et al., "Whole brain radiation therapy with or without stereotactic radiosurgery boost for patients with one to three brain metastases: phase III results of the RTOG 9508 randomised trial," The Lancet, vol. 363, no. 9422, pp. 1665-1672, 2004.

[144] S. Yoshida, K. Morii, M. Watanabe, T. Saito, F. F. Lang, and R. Sawaya, "Brain metastasis in patients with sarcoma: an analysis of histological subtypes, clinical characteristics, and outcomes," Surgical Neurology, vol. 54, no. 2, pp. 160-164, 2000.

[145] M. J. Krasin, A. M. Davidoff, X. Xiong et al., "Preliminary Results From a Prospective Study Using Limited Margin Radiotherapy in Pediatric and Young Adult Patients With HighGrade Nonrhabdomyosarcoma Soft-Tissue Sarcoma," International Journal of Radiation Oncology Biology Physics, vol. 76, no. 3, pp. 874-878, 2010.

[146] W. T. van der Graaf, J. Y. Blay, S. P. Chawla et al., "Pazopanib for metastatic soft-tissue sarcoma (PALETTE): a randomised, double-blind, placebo-controlled phase 3 trial," The Lancet, vol. 379, no. 9829, pp. 1879-1886, 2012.

[147] K. Mineura, T. Yasuda, Y. Suda, M. Kowada, F. Shishido, and K. Uemura, "Ewing's sarcoma with intracranial metastasis presenting depressed cerebral blood flow and metabolism in the contralateral gray matter," Computerized Medical Imaging and Graphics, vol. 13, no. 2, pp. 185-190, 1989. 


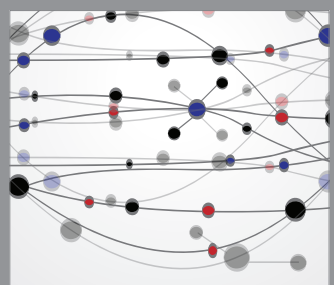

The Scientific World Journal
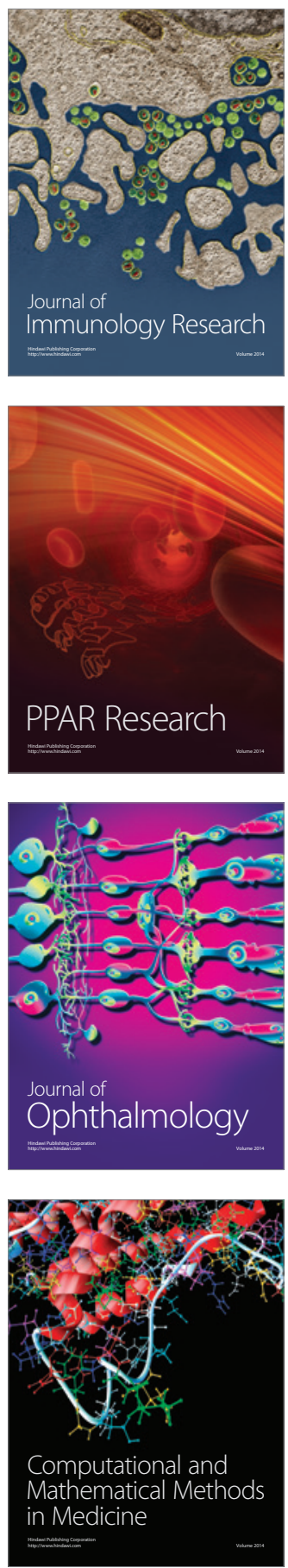

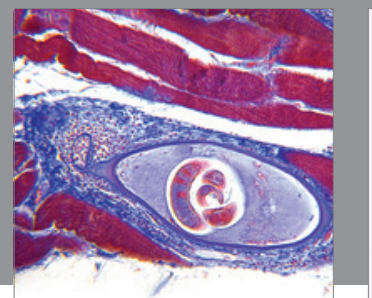

Gastroenterology

Research and Practice
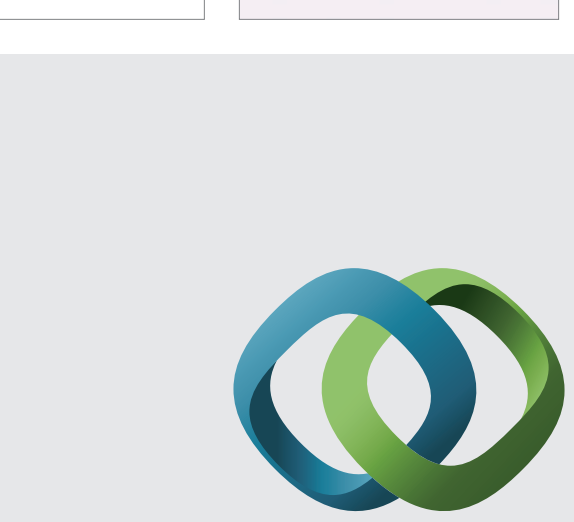

\section{Hindawi}

Submit your manuscripts at

http://www.hindawi.com
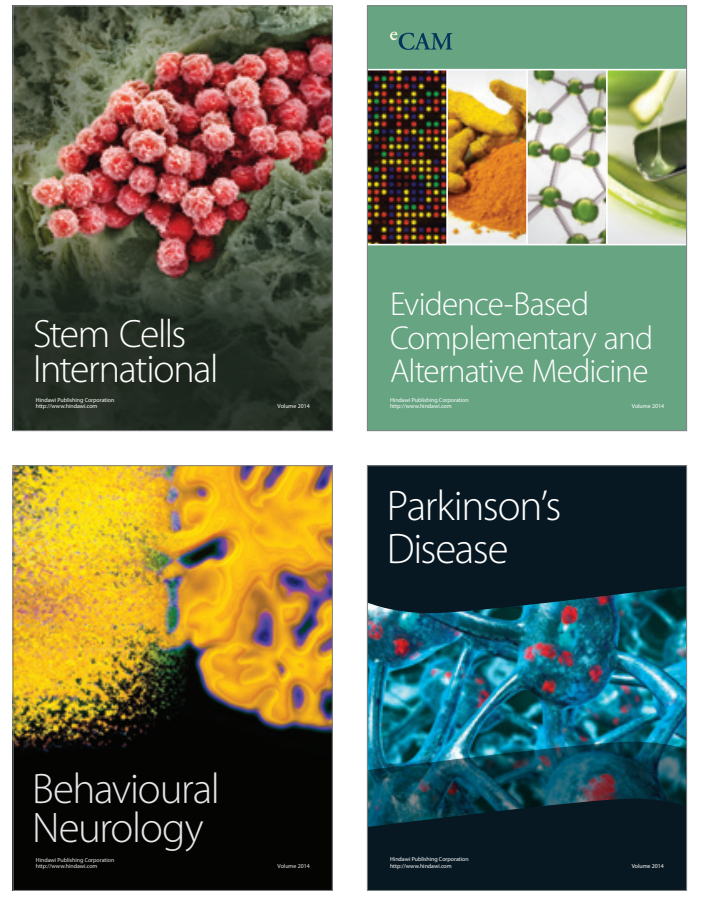
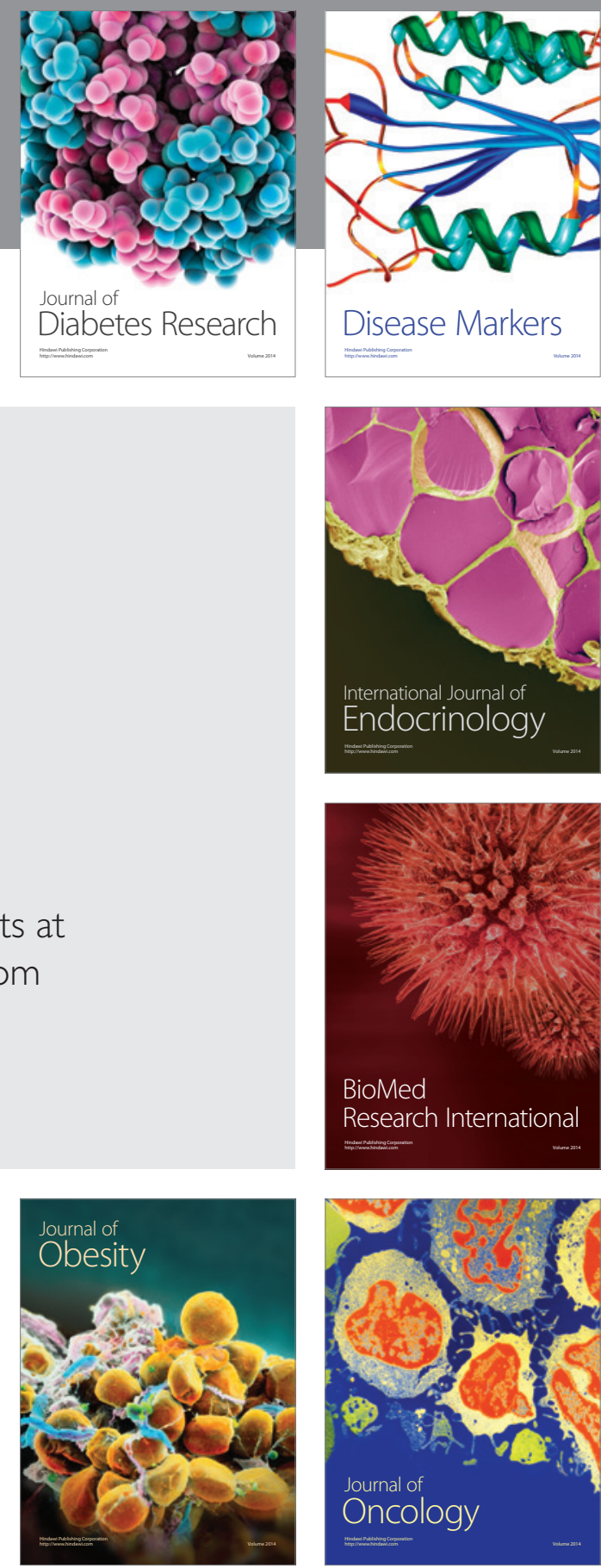

Disease Markers
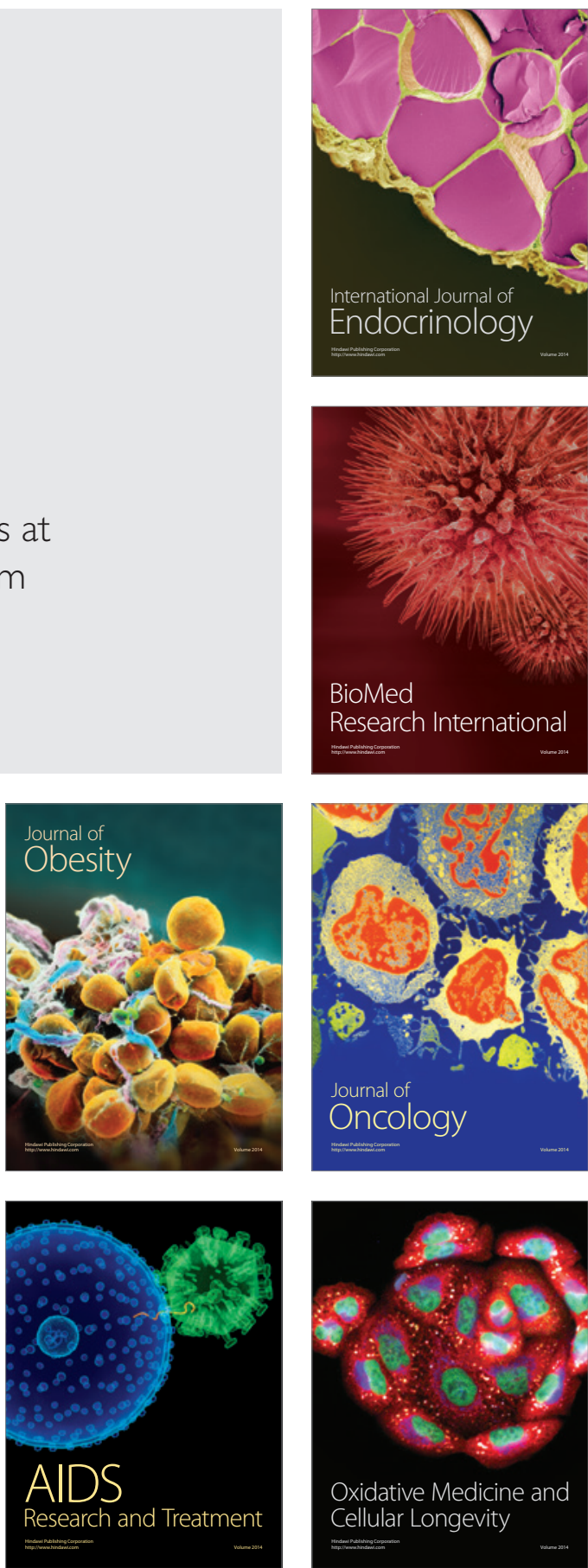